\title{
UNCERTAINTY SHOCKS ARE AGGREGATE DEMAND SHOCKS
}

\author{
SYLVAIN LEDUC AND ZHENG LIU
}

\begin{abstract}
We present empirical evidence and a theoretical argument that uncertainty shocks act like a negative aggregate demand shock, which raises unemployment and lowers inflation. We measure uncertainty using survey data from the United States and the United Kingdom. We estimate the macroeconomic effects of uncertainty shocks in a vector autoregression (VAR) model, exploiting the relative timing of the surveys and macroeconomic data releases for identification. Our estimation reveals that uncertainty shocks accounted for at least one percentage point increases in unemployment in the Great Recession and recovery, but did not contribute much to the 1981-82 recession. We present a DSGE model to show that, to understand the observed macroeconomic effects of uncertainty shocks, it is essential to have both labor search frictions and nominal rigidities.
\end{abstract}

\section{INTRODUCTION}

Since the Great Recession, there has been a rapidly growing strand of literature - led by the influential work of Bloom (2009) - that studies the macroeconomic effects of uncertainty shocks. Most of the studies focus on the effects of uncertainty on real economic activity such as investment and output. Less is known about the joint effects of uncertainty on inflation and unemployment, and thus about the role of monetary policy in an environment with heightened uncertainty.

In this paper, we provide some empirical evidence and a theoretical argument that uncertainty shocks consistently act like aggregate demand shocks, which raise unemployment and

Date: January 29, 2013.

Key words and phrases. Uncertainty, Demand shocks, Unemployment, Inflation, Monetary policy, Survey data.

JEL classification: E21, E27, E32.

Leduc: Federal Reserve Bank of San Francisco; Email: Sylvain.Leduc@sf.frb.org. Liu: Federal Reserve Bank of San Francisco; Email: Zheng.Liu@sf.frb.org. We thank Susanto Basu, Nick Bloom, Toni Braun, Mary Daly, John Fernald, Jesús Fernández-Villaverde, Cristina Fuentes-Albero, Simon Gilchrist, Bart Hobjin, Giorgio Primiceri, Federico Ravenna, Juan F. Rubio-Ramírez, Pedro Silos, Pengfei Wang, John Williams, Tao Zha and seminar participants at the Federal Reserve Banks of Atlanta and San Francisco, the Bank of Canada, the Canadian Macro Study Group, the 2012 NBER Productivity and Macroeconomics meeting, and the 2012 NBER Workshop on Methods and Applications for Dynamic Stochastic General Equilibrium Models. We are grateful to Tao Zha for providing us with his computer code for estimating Bayesian VAR models. The views expressed herein are those of the authors and do not necessarily reflect the views of the Federal Reserve Bank of San Francisco or the Federal Reserve System. 
lower inflation. Since both inflation and economic activity declines, policymakers react to an increase in uncertainty by lowering the nominal interest rate both in our model and in the data.

Despite the importance attached to uncertainty shocks, formal empirical studies on how uncertainty shocks impact upon macroeconomic fluctuations remain scant. To fill this gap in the literature, we provide evidence on the effects of uncertainty shocks on the macro economy, using direct measures of perceived uncertainty by consumers and firms from survey data in vector-autoregression (VAR) models.

Specifically, we construct measures of uncertainty using data from the University of Michigan Survey of Consumers in the United States and the Confederation of British Industry (CBI) Industrial Trends Survey of firms in the United Kingdom. Both surveys tally responses that make explicit references to "uncertainty" in affecting consumers' decisions to buy durable goods such as cars in the U.S. or firms' decisions on capital expenditures in the U.K.. We exploit the timing of the surveys' construction to help identify structural shocks to uncertainty. We examine their effects on three macroeconomic time series: the unemployment rate, the CPI inflation rate, and the three-month T-bill rate.

A robust result that emerges from our study is that an increase in uncertainty raises unemployment and lowers inflation and short-term nominal interest rates. The negative comovement between the responses of unemployment and inflation suggests that uncertainty acts like a negative aggregate demand shock, for which policymakers accommodate by lowering the nominal interest rate. This pattern occurs in both the United States and in the United Kingdom. It holds for different identification strategies. It also holds for a few alternative measures of uncertainty, including the VIX index studied by Bloom (2009) and the policy uncertainty index proposed by Baker, Bloom, and Davis (2011). We show that the results are robust to controlling for movements in consumer confidence, expected future income, or credit spreads, variables that can potentially mitigate the effects of uncertainty shocks empirically (see, for instance, Gilchrist et al (2010) and Baker, Bloom, and Davis (2011)).

We also find evidence that uncertainty can deepen recessions and hinder recoveries in quantitatively important ways. In our benchmark VAR model with the household-survey based measure of perceived uncertainty, uncertainty shocks account for at least one percentage point increase in the unemployment rate from the fall of 2008 through the end of our sample in the first half of 2012. Our survey-based measure of uncertainty is broad and does not isolate a particular source of uncertainty. When we use a finer measure of uncertainty related to economic policy proposed by Baker, Bloom, and Davis (2011), we find 
that uncertainty shocks continue to be an important factor explaining the sharp increase in unemployment in the Great Recession and recovery.

Interestingly, uncertainty shocks did not always play an important role during previous recessions and recoveries. For example, uncertainty shocks contributed very little to the sharp increase in unemployment during the 1981-82 recession. This latter finding accords well with the view that monetary policy tightening under Fed Chairman Paul Volcker may have played a more important role in that recession.

To help understand the mechanisms through which uncertainty shocks can be propagated to generate the observed demand-shock like effects in the macroeconomy, we study a dynamic stochastic general equilibrium (DSGE) model that incorporates labor search frictions and nominal rigidities. Incorporating labor market frictions in the DSGE model enables us to examine the effects of uncertainty shocks on unemployment explicitly. More importantly, we show that uncertainty shocks can be substantially amplified through interactions between search frictions and nominal rigidities.

The model economy is populated by a large number of identical and infinitely lived households. The representative household is a family of workers, some are employed and the others are not. In each period, unemployed workers search for jobs and firms post vacancies at a fixed cost, with a matching technology transforming searching workers and vacancies into new job matches. When a match is formed, a wage is determined from a Nash bargaining game between the new firm and the household. In each period, a fraction of employed workers is separated exogenously from their matches. Thus, aggregate employment in a given period is the sum of the number of workers that survive separation and the number of new matches formed. ${ }^{1}$

To introduce nominal rigidities, we follow Blanchard and Galí (2010) and assume that there is a retail sector, in which a large number of retailers produce differentiated retail products using the homogenous intermediate good produced by firms as input. While the intermediate good market is perfectly competitive, the retail goods market is monopolistically competitive. The final consumption good is a Dixit-Stiglitz composite of the differentiated retail products. Each retailer sets a price for its own product subject to a price adjustment cost (Rotemberg, 1982). The retailer takes the price index and the demand schedule for its product as given. Monetary policy follows a feedback interest rate rule (i.e., a Taylor rule), under which the nominal interest rate reacts to deviations of inflation from a target and also to fluctuations in output gap.

\footnotetext{
${ }^{1}$ The type of search friction that we consider here takes its root from the original contributions by Diamond (1982) and Mortensen and Pissarides (1994).
} 
Since the demand-shock like effects of uncertainty shocks hold for a broad set of measures of uncertainty in our empirical work, we consider three types of uncertainty in our model related to preferences, technology, and fiscal policy. We find that, consistent with our empirical results, a rise in uncertainty - regardless of its source - is always contractionary and always lowers inflation. Under the Taylor rule, the monetary authority reacts to the declines in output and inflation by lowering the nominal interest rate.

Our model suggests that labor search frictions and nominal rigidities are both important for amplifying the macroeconomic effects of uncertainty shocks. For example, absent nominal rigidities, a technology uncertainty shock generates a response of unemployment that is about one sixth as large as that in our benchmark model. Similarly, absent significant search frictions, the effects of a technology uncertainty shock on unemployment is about one third as large as in the benchmark model.

Nominal rigidities help amplify the effect of uncertainty shocks in a DSGE model through variations in markups (Fernández-Villaverde, Guerrón-Quintana, Kuester, and Rubio-Ramírez, 2011; Basu and Bundick, 2011). With sticky prices, an uncertainty shock that lowers aggregate demand also lowers the relative price of intermediate goods, which corresponds to the inverse of the markup in the retail sector. The decline in the relative price reduces the value of a new match, so that firms post fewer job vacancies and the unemployment rate rises. As more searching workers fail to find a job match, the household's income declines further, leading to an even greater fall in aggregate demand, which reinforces the initial decline in the relative price, creating a multiplier effect that amplifies uncertainty shocks to generate large macroeconomic fluctuations. This amplification mechanism is absent in the flexible-price model, since the relative price is constant.

Search frictions in the labor market provide an additional mechanism for uncertainty shocks to generate large increases in unemployment. This mechanism reflects the impact of uncertainty shocks on the value of a job match and the shape of the Beveridge curve, which captures the negative and convex relationship between vacancies and unemployment. When the cost of posting a vacancy is very low, which would approximate a frictionless labor market, equilibrium unemployment is determined along a relatively inelastic segment of the Beveridge curve. In this case, a rise in uncertainty lowers the value of a filled vacancy; but for any given decline in posted vacancies, the increase in unemployment is muted. However, when the cost of posting vacancies is high (i.e., when search frictions are more important), a given decline in posted vacancies would be associated with a much larger increase in unemployment, since equilibrium unemployment is determined along a relatively more elastic segment of the Beveridge curve. Thus, in our model, search frictions have important interactions with sticky prices to amplify uncertainty shocks. 
Our work adds to the recent rapidly growing literature that studies the macroeconomic effects of uncertainty shocks in a DSGE framework. For example, Bloom, Floetotto, Jaimovich, Saporta-Eksten, and Terry (2012) study a DSGE model with heterogeneous firms and nonconvex adjustment costs in productive inputs. They find that a rise in uncertainty makes firms pause hiring and investment and thus leads to a large drop in economic activity. Christiano, Motto, and Rostagno (2012) present a DSGE model with a financial accelerator in the spirit of Bernanke, Gertler, and Gilchrist (1999). They find that risk shocks (i.e., changes in the volatility of cross-sectional idiosyncratic uncertainty) play an important role for shaping U.S. business cycles. Barro (2006) shows that rare disasters - a form of risk shocks - help reconcile some asset pricing puzzles in business cycle models (see also Gabaix (2012) and Gourio (2012)). Gilchrist, Sim, and Zakrajsek (2010) and Arellano, Bai, and Kehoe (2011) argue that uncertainty shocks have important interactions with financial factors. Related to the general issue of uncertainty and risks, Ilut and Schneider (2011) examine the macroeconomic implications of ambiguity aversion in an estimated medium-scale DSGE model. ${ }^{2}$

Our work is closely related to Fernández-Villaverde, Guerrón-Quintana, Kuester, and Rubio-Ramírez (2011), who examine the effects of fiscal policy uncertainty and find that it can trigger sizable adverse effects on economic activity in a model with price and wage rigidities, particularly in the case of uncertainty about taxes on capital income. Our work is also closely related to the study by Basu and Bundick (2011), who focus on the importance of nominal rigidities to generate comovement between macroeconomic variables following an uncertainty shock. We share a similar emphasis with these studies that uncertainty shocks work through an aggregate demand channel in the presence of nominal rigidities. We further point out that the macroeconomic effects of uncertainty can be substantially amplified by search frictions in the labor market. This point, to our knowledge, is new to the literature.

Most of the studies in the literature abstract from labor search frictions and are not designed to examine the impact of uncertainty shocks on labor market dynamics such as unemployment and job vacancies. An exception is Schaal (2012), who presents a model with labor search frictions and idiosyncratic volatility shocks to study the observation in the Great Recession period that high unemployment was accompanied by high labor productivity. As

\footnotetext{
${ }^{2}$ The literature suggests that rising uncertainty may hinder irreversible investment and hiring decisions, because it raises the option value of waiting. For partial equilibrium analyses of the real option value theory in the context of uncertainty shocks, see, for example, (Bernanke, 1983) and Bloom (2009). Romer (1990) argues that increases in uncertainty following the stock market crash in 1929 contributed to worsening the Great Depression by substantially reducing demand for consumer durable goods. For empirical evidence on the effects of uncertainty on investment, see, for example, Leahy and Whited (1996) and Guiso and Parigi (1999). For a comprehensive survey of the literature on uncertainty shocks, see Bloom and FernandezVillaverde (2012).
} 
in the other studies discussed here, he focuses on the effects of uncertainty on real activity, not on its interaction with inflation and monetary policy. In addition, he assumes that uncertainty shocks are negatively correlated with aggregate productivity, so that such shocks can have important recessionary effects. In our model, we do not assume correlations between uncertainty shocks and the level of aggregate productivity; instead, uncertainty shocks are amplified through interactions between nominal rigidities and labor search frictions.

In what follows, we present in Section II empirical evidence that uncertainty shocks consistently act like an aggregate demand shock. We then present in Section III a DSGE model with labor search frictions and sticky prices. We discuss in Section IV the dynamic effects of uncertainty shocks on unemployment and other macroeconomic variables in the calibrated DSGE model. We provide some concluding remarks in Section V.

\section{The Macroeconomic Effects of Uncertainty Shocks: Evidence}

In this section, we examine the macroeconomic effects of uncertainty shocks in the data. We first present two new measures of uncertainty from survey data. We then estimate a VAR model that includes a measure of uncertainty and a few macroeconomic variables. VAR models are used in the literature as a main statistical tool to estimate the responses of macroeconomic variables to uncertainty shocks. Examples include Alexopoulos and Cohen (2009), Bloom (2009), Bachmann, Elstner, and Sims (2011), and Baker, Bloom, and Davis (2011). Existing studies focus on the effects of uncertainty on real economic activity such as employment, investment, and output. We focus on the joint effects of uncertainty on unemployment and inflation.

II.1. Measures of uncertainty. We consider two new measures of uncertainty from survey data, including a measure of perceived uncertainty by consumers from the Michigan Survey of Consumers and a measure of perceived uncertainty by firms from the CBI Industrial Trends Survey in the United Kingdom. Since these two survey-based measures of uncertainty are new in the literature, we begin with some explanations of how these measures are constructed in the survey.

Each month since 1978, the Michigan Survey has been conducting interviews of about 500 households throughout the United States, asking questions ranging from their perceptions of business conditions to expectations for future movements in prices. More important for our analysis, the survey tallies the fraction of respondents who report that "uncertain future" is a factor that will likely limit their expenditures on cars or other durable goods over the next 12 months. $^{3}$

\footnotetext{
${ }^{3}$ The question on vehicle purchases is, "Speaking now of the automobile market-do you think the next 12 months or so will be a good time or a bad time to buy a vehicle, such as a car, pickup, van or sport utility
} 
Figure 1 shows the time-series plots of consumers' perceived uncertainty (concerning vehicle purchases) along with the VIX index - a commonly used measure of uncertainty in the literature (Bloom, 2009). Similar to the VIX index, consumers' perceived uncertainty is countercyclical. It rises in recessions and falls in expansions. A notable difference between the consumers' perceived uncertainty and financial uncertainty measured by the VIX is that the 1997 East-Asian financial crisis and the 1998 Russian debt crisis led to large spikes in the VIX, but did not seem to have much impact on consumer perceptions of uncertainty. Another notable difference is that, in the more recent months in 2012, the VIX index has stayed at low levels despite of the looming "fiscal cliff" that would trigger large increases in taxes and substantial cuts in government spending if the Congress and the White House cannot reach an agreement for deficit cuts. However, consumer uncertainty from the Michigan survey has remained elevated during this period. ${ }^{4}$

We follow a similar procedure to construct firms perceived uncertainty from the CBI Industrial Trends Survey in the United Kingdom. Each quarter since 1978, the CBI has been surveying a large sample of roughly 1,100 firms in the United Kingdom in each quarter. We measure firms' perceived uncertainty as the fraction of firms that report "uncertainty about demand" as a factor limiting their capital expenditures over the next 12 months. ${ }^{5}$

As Figure 2 shows, firms' perceived uncertainty is also countercyclical, but it appears relatively more stable than what is reported by the Michigan survey of consumers. This difference may reflect the fact that U.K. firms are asked about a specific form of uncertainty (i.e., about the demand for their products), whereas no such specificity is attached to the measure of uncertainty in the Michigan survey.

II.2. Empirical results. We now examine the macroeconomic effects of uncertainty shocks by estimating a Baysian vector autoregression (BVAR) model. Sims and Zha (1998) argue that sampling errors can lead to difficulties in estimating error bands for impulse responses in a VAR model with a short time-series sample of data. They propose using Baysian priors (instead of flat priors) to help improve the estimation of error bands. We follow their approach in our analysis.

In our benchmark VAR model, we consider four variables, including a measure of uncertainty, the unemployment rate, the inflation rate measured as the year-over-year change in vehicle? Why do you say so?" Reasons related to uncertainty are then compiled. The series is weighted by age, income, region, and sex to be nationally representative.

${ }^{4} \mathrm{~A}$ possible explanation is that the VIX index focuses on short-term uncertainty because it is a weighted average of 30-day ahead option prices.

${ }^{5}$ The question asked by the CBI is, "What factors are likely to limit (wholly or partly) your capital expenditure authorisations over the next twelve months?" Participants can choose "uncertainty about demand" as one of six options. Firms can provide other reasons or choose multiple reasons. 
the consumer price index (CPI), and the three-month Treasury bills rate. The sample ranges from January 1978 to November 2012.

In our benchmark VAR model, we exploit the timing of survey interviews relative to the timing of macroeconomic data releases for identification. To examine the robustness of our results, we also consider alternative identification schemes in Section II.4.2. In the Michigan survey, phone interviews are conducted throughout the month, with most interviews concentrated in the middle of each month, and preliminary results released shortly thereafter. The final results are typically released by the end of the month. When answering questions, survey participants have information about the previous month's unemployment, inflation, and interest rates, but they do not have (complete) information about the current-month macroeconomic conditions because the macroeconomic date have not yet been made public. Hence, our identification strategy uses the fact that when answering questions at time $t$ about their expectations of the future, the information set on which survey participants condition their answers will not include, by construction, the time $t$ realizations of the unemployment rate and the other variables in our VAR. ${ }^{6}$ Thus, we follow the approach in Leduc, Sill, and Stark (2007), Auerbach and Gorodnichenko (2012), and Leduc and Sill (forthcoming) by placing the uncertainty measure as the first variable in the VAR. This Cholesky ordering implies that uncertainty does not respond to macroeconomic shocks in the impact period, while unemployment, inflation, and the nominal interest rate are allowed to change on impact of an uncertainty shock. ${ }^{7}$

We first look at the transmission of uncertainty shocks in the Unites States using the measure of consumer uncertainty from the Michigan Survey. Figure 3 presents the impulse responses in the VAR model, in which consumer uncertainty is ordered first. For each variable, the solid line denotes the median estimate of the impulse response and the dashed lines represent the range of the 90 -percent confidence band around the point estimates. The figure shows that an unexpected increase in uncertainty leads to a persistent increase in the unemployment rate, which reaches a peak in about 18 months from the impact period and remains significantly positive for about three years. Heightened uncertainty also leads to a

\footnotetext{
${ }^{6}$ Similarly, the questionnaires for the CBI survey must be returned by the middle of the first month of each quarter. The design of the survey implies that participants have information about the values of the variables in the VAR for the previous quarter when they filled in answers to the survey questions, but they do not know the macroeconomic data in the current quarter.

${ }^{7}$ Bachmann and Moscarini (2011) argue that bad first-moment shocks can raise cross-sectional dispersions and time-series volatility of macroeconomic variables. In this sense, changes in measured uncertainty could reflect endogenous responses of macroeconomic variables to first-moment shocks. Our empirical approach allows measured uncertainty to react to macroeconomic shocks, but it also presumes that measured uncertainty contains some exogenous component.
} 
significant and persistent decline in inflation, with the peak effect also occurring roughly 18 months after the shock.

The aggregate demand effect of uncertainty is not unique to the U.S. economy. It is also present in the U.K. data. Using the measure of firms' perceived uncertainty from the CBI Survey, we examine the effects of uncertainty shocks in a VAR model using UK data on unemployment, inflation, and the three-month nominal interest rate. Since the survey data are quarterly, we convert the unemployment rate, the inflation rate, and the 3-month nominal interest rate from monthly to quarterly frequency by taking the end of quarter observations (e.g., unemployment for the first quarter of 1980 is the unemployment rate in March 1980 and for the second quarter, it is that in June, and so on). The sample ranges from 1979:Q4 to 2011:Q2. Figure 4 shows that an unanticipated increase in the level of uncertainty leads to persistent increases in unemployment and persistent declines in both the inflation rate and the nominal interest rate in the U.K. sample, just as those observed in the U.S. data.

II.3. Quantitative importance of uncertainty shocks. How important are uncertainty shocks for macroeconomic fluctuations? This question is important, especially in light of the recent discussions about potential consequences of going over the fiscal cliff for the United States economy. We have seen that the estimated impulse responses of unemployment to an uncertainty shock are statistically significant. Those impulse responses, however, reflect the average effects of an increase in uncertainty on unemployment in the entire sample; they do not indicate the relative importance of uncertainty shocks for unemployment in different recessions. Our sample of U.S. data covers 4 different recessions, with particularly large increases in unemployment in 2 of them: one in the early 1980s and the other during the Great Recession and recovery periods since 2008. We focus on these 2 recessions and ask the question: How much of the observed increases in unemployment in each of these recessions are accounted for by increases in the levels of uncertainty?

To provide an answer to this question, we calculate historical decompositions from our estimated VAR model. This calculation is a counterfactual experiment. By construction, if we have all 4 shocks turned on in our benchmark 4-variable VAR model, the estimated VAR model would exactly match the observed time series of the unemployment rate. The counterfactual experiment that we conduct is one in which we turn off all shocks but the uncertainty shock in the VAR model and calculate the implied unemployment path in each of the two recession periods.

Figure 5 shows the changes in the unemployment rate during the Great Recession and recovery period (the top panel) and those in the 1981-82 recession (the bottom panel). The thin blue lines indicate the actual increases in the unemployment rate (relative to the benchmark with no shocks) in each of the two recessions; the red bars indicate the simulated 
unemployment rate when all 4 shocks are turned on (and, by construction, they match the actual data exactly); and the blue bars indicate the simulated changes in the unemployment rate conditional on the estimated uncertainty shocks alone.

The figure reveals that uncertainty shocks have contributed about 30-40\% of the actual increases in the unemployment rate in the Great Recession and recovery. In particular, out of the 3-4 percentage point increases in unemployment from 2008 through the end of our sample in 2012, about 1-1.5 percentage points are accounted for by heightened uncertainty.

A possible reason why uncertainty shocks contributed to large increases in unemployment in the Great Recession and recovery is that monetary policy has been constrained by the zero lower bound on the nominal interest rate during this period. This view is consistent with Basu and Bundick (2011), who find that, in a calibrated DSGE model, the adverse effects of uncertainty shocks on aggregate output are substantially amplified when the policy rate reaches the zero lower bound.

In contrast, uncertainty shocks contributed little to the surge in unemployment during the 1981-82 recession period. This latter finding is consistent with the view that monetary policy tightening under Fed Chairman Paul Volcker was an important driving force of the recession in the early 1980 s. $^{8}$

II.4. Robustness. The finding that uncertainty shocks act like aggregate demand shocks is fairly robust. As we have just demonstrated, it holds for data in both the United States and the United Kingdom, with two different measures of uncertainty (one reflects consumers' perceptions of uncertainty in the U.S. and the other captures firms' perceptions in the U.K.) that display relatively different time-series properties. We now show that the results are also robust to alternative measures of uncertainty, alternative identification assumptions, and inclusions of additional macroeconomic variables in the VAR model.

II.4.1. Alternative measures of uncertainty. There are a few other measures of uncertainty used in the literature. We focus on two particular measures, including the VIX index that captures the stock price volatility, which, as shown by Bloom (2009), leads to substantial declines in industrial output and employment in the short run; and the economic policy uncertainty index constructed by Baker, Bloom, and Davis (2011), who show that a shock to policy uncertainty foreshadows large declines in industrial output and employment.

\footnotetext{
${ }^{8}$ Similarly, uncertainty shocks did not contribute much to unemployment in the 2001 recession. However, we do find that uncertainty shocks played a major role during and following the 1990-1991 recession. One possibility is that this recession involved a military conflict in the Middle East, which might have ignited fears of potentially catastrophic events such as disruptions of oil supply. Since the increases in unemployment in these two episodes of recession were relatively small, we focus on the quantitative effects of uncertainty on unemployment in the Great Recession and the 1981-82 recession.
} 
Our sample size depends on the measure of uncertainty. The VIX index constructed by the Chicago Board of Exchange (CBOE) has a sample that starts in January 1990. We extend the series back in time (for the pre-1990 periods) using the CBOE's VXO index, which starts in January 1986. The policy uncertainty index is a monthly series that starts in January 1985. The ending period for both these uncertainty measures is November 2012.

Figure 6 shows that, when the uncertainty measure in our benchmark model is replaced by the VIX index, an uncertainty shock raises unemployment and lowers inflation and the nominal interest rate, just as what we observe when we use the survey-based measure of uncertainty. Similarly, when we use the economic policy uncertainty index constructed by Baker, Bloom, and Davis (2011), we obtain qualitatively identical results (see Figure 7). In both cases, the responses of macroeconomic variables are statistically significant at the 90 percent level. Thus, our finding that an uncertainty shock acts like a negative aggregate demand shock is robust to these alternative measures of uncertainty.

II.4.2. Alternative identification approaches. We now examine the sensitivity of our results to alternative identification assumptions.

Although the timing of the survey relative to macroeconomic data releases suggests that survey respondents do not possess complete information about the current-month macroeconomic data at the time of the interviews (which substantiates our Cholesky identification assumption in the benchmark VAR model), it is possible that they observe other, possibly higher-frequency variables that give them information about the time $t$ realizations of the variables in the VAR model. We thus estimate a VAR model with uncertainty ordered last. This relatively conservative identification assumption implies that the measure of uncertainty is allowed to respond to contemporaneous macroeconomic shocks.

Figure 8 presents the impulse responses in the VAR model with consumer uncertainty (from the Michigan Survey) ordered last. The responses of the three macroeconomic variables to an uncertainty shock look remarkably similar to those in the baseline VAR with uncertainty ordered first. Under each identification strategy, a positive uncertainty shock acts like a negative aggregate demand shock that raises unemployment and lowers inflation. In response to the recessionary effects of uncertainty shocks, monetary policy reacts by easing the stance of policy and lowering the nominal interest rate.

To further examine the sensitivity of our results to the identification assumptions, we estimate a VAR model with uncertainty measured by a dummy variable that takes a value of one if there is an uncertainty event in a particular month and zero otherwise, where most of the uncertainty events are identified by Bloom (2009). ${ }^{9}$ In estimating this VAR model, we

\footnotetext{
${ }^{9}$ Bloom (2009) identifies 17 uncertainty events for the periods from 1962 to 2008 . To be consistent with our benchmark VAR model, we focus on the sample from January 1978 to November 2012. Our sample
} 
follow Bloom (2009) and treat the uncertainty dummy as an exogenous variable, which does not respond to changes in macroeconomic conditions. Figure 9 shows the impulse responses of the macroeconomic variables following a shock to the uncertainty dummy. The figure shows that an uncertainty shock leads to significant short-run increases in unemployment and significant declines in inflation and the nominal interest rate, although the macroeconomic responses are less persistent than those estimated from our benchmark VAR model with consumer uncertainty. This finding lends further support to our view that uncertainty shock acts like an aggregate demand shock.

II.4.3. Larger VAR models. To further examine the robustness of our results, we estimate a few alternative VAR models that include additional macroeconomic variables. For ease of comparison, we use consumers' perceived uncertainty from the University of Michigan survey in each model and we impose the same Cholesky identification restrictions as in our benchmark model by ordering uncertainty first in these alternative VAR models.

One such larger VAR model includes, in addition to the 3 macroeconomic time series, a measure of labor market tightness (measured by the ratio of the job vacancy rate to the unemployment rate, or the $\mathrm{v}-\mathrm{u}$ ratio). We measure job vacancies using data from JOLTS combined with the Help-Wanted Index published by the Conference Board. The sample range is the same as in our benchmark VAR model (from January 1978 to November 2012). Figure 10 shows that an unexpected rise in uncertainty leads to a significant and persistent increase in the unemployment rate and persistent declines in the v-u ratio. As in the benchmark model, the shock also lowers both the inflation rate and the nominal interest rate. These observations, as we show in the theory section, are consistent with a DSGE model with nominal rigidities and search frictions in the labor market. An uncertainty shock in this larger VAR model continues to have macroeconomic effects that are similar to a negative aggregate demand shock.

We have estimated other models that, in addition to the four variables in our baseline VAR model (with consumer uncertainty ordered first), also include (i) consumption of nondurables and services and business fixed investment; (ii) credit spread and stock price index; or (iii) full-time and part-time employment. We have also estimated the baseline four-variable VAR model with the sample ending at the end of 2008, before the policy rates in the United States

includes 11 uncertainty events taken from Bloom (2009) for the period between 1978 and 2008 (see his Table A.1). We extend the sample to include a new uncertainty event that occurred in August 2011, when the debt ceiling dispute triggered a downgrade of the United States government debt. 
and the United Kingdom hit the zero lower bound. In each case, uncertainty shocks consistently act like an aggregate demand shock that raises unemployment and lowers inflation and the nominal interest rate. ${ }^{10}$

II.5. Uncertain future or bad economic times? As shown in Figure 1, consumer uncertainty rises in recessions and falls in booms. A priori, it is possible that consumer uncertainty from the Michigan survey may reflect the respondents' perceptions of "bad economic times" rather than "uncertain future."

To examine to what extent consumer uncertainty might reflect their perceptions of bad economic times, we examine to what extent the macroeconomic effects of shocks to consumer uncertainty may reflect the responses to changes in other indicators of economic conditions, such as consumer confidence. For this purpose, we follow a similar approach in Baker, Bloom, and Davis (2011) and estimate a 5-variable VAR model that includes a consumer sentiment index as an additional variable to control for potential effects from movements in consumer confidence.

Figure 11 shows that the macroeconomic effects of uncertainty shocks are qualitatively similar to those estimated from the benchmark VAR. Following an exogenous increase in uncertainty, consumer sentiment declines, unemployment rises, and inflation and the nominal interest rate both fall. The responses of the macroeconomic variables are statistically significant at the 90 percent level. Thus, the macroeconomic effects of consumer uncertainty shocks do not seem to reflect responses of macroeconomic variables to changes in consumer confidence. ${ }^{11}$

\section{UNCERTAINTY SHOCKS IN A DSGE MODEL WITH SEARCH FRICTIONS}

In this section, we examine the channels of transmission for uncertainty shocks to affect the macroeconomy in a DSGE model with sticky prices and labor market search frictions. We show that uncertainty shocks in the DSGE model act like an aggregate demand shock that raises unemployment, lowers inflation, and through the Taylor rule, lowers the nominal interest rate, just as what we have seen in the data. We further show that search frictions in the labor market and sticky prices in the goods market are both important for amplifying the effects of uncertainty shocks in the model.

\footnotetext{
${ }^{10}$ To conserve space, we do not report the impulse response figures in the paper. These figures are included in a supplemental appendix.

${ }^{11}$ The consumer sentiment index that we use here is a measure of consumer sentiment about current economic conditions. We have also estimate a 5 -variable VAR model by using the consumer sentiment index for expectations. The qualitative results are also very similar to those in the benchmark VAR model.
} 
The model builds on the basic framework in Blanchard and Galí (2010). We focus on the effects of uncertainty shocks. The economy is populated by a continuum of infinitely lived and identical households with a unit measure. The representative household consists of a continuum of worker members. The household owns a continuum of firms, each of which uses one worker to produce an intermediate good. In each period, a fraction of the workers are unemployed and they search for a job. Firms post vacancies at a fixed cost. The number of successful matches are produced with a matching technology that transforms searching workers and vacancies into an employment relation. Real wages are determined by Nash bargaining between a searching worker and a hiring firm.

The household consumes a basket of differentiated retail goods, each of which is transformed from the homogeneous intermediate good using a constant-returns technology. Retailers face a perfectly competitive input market (where they purchase the intermediate good) and a monopolistically competitive product market. Each retailer sets a price for its differentiated product, with price adjustments subject to a quadratic cost in the spirit of Rotemberg (1982).

The government finances its spending and transfer payments to unemployed workers by distortionary taxes on firm profits. Monetary policy is described by the Taylor rule, under which the nominal interest rate responds to deviations of inflation from a target and of output from its potential.

III.1. The households. There is a continuum of infinitely lived and identical households with a unit measure. The representative household consumes and invests a basket of retail goods. The utility function is given by

$$
E \sum_{t=0}^{\infty} \beta^{t} A_{t}\left(\ln C_{t}-\chi N_{t}\right)
$$

where $E[\cdot]$ is an expectation operator, $C_{t}$ denotes consumption, and $N_{t}$ denotes the fraction of household members who are employed. The parameter $\beta \in(0,1)$ denotes the subjective discount factor and the parameter $\chi$ measures the disutility from working.

The term $A_{t}$ denotes an intertemporal preference shock. Let $\gamma_{a t} \equiv \frac{A_{t}}{A_{t-1}}$ denote the growth rate of $A_{t}$. We assume that $\gamma_{a t}$ follows the stochastic process

$$
\ln \gamma_{a t}=\rho_{a} \ln \gamma_{a, t-1}+\sigma_{a t} \varepsilon_{a t} .
$$

The parameter $\rho_{a} \in(-1,1)$ measures the persistence of the preference shock. The term $\varepsilon_{a t}$ is an i.i.d. standard normal process. The term $\sigma_{a t}$ is a time-varying standard deviation of the innovation to the preference shock. We interpret it as a preference uncertainty shock. 
We assume that $\sigma_{a t}$ follows the stationary process

$$
\ln \sigma_{a t}=\left(1-\rho_{\sigma_{a}}\right) \ln \sigma_{a}+\rho_{\sigma_{a}} \ln \sigma_{a, t-1}+\sigma_{\sigma_{a}} \varepsilon_{\sigma_{a}, t},
$$

where $\rho_{\sigma_{a}} \in(-1,1)$ measures the persistence of preference uncertainty, $\varepsilon_{\sigma_{a}, t}$ denotes the innovation to the preference uncertainty shock and is a standard normal process, and $\sigma_{\sigma_{a}}$ denotes the (constant) standard deviation of the innovation.

The representative household is a family consisting of a continuum of workers with a unit measure. The family chooses consumption $C_{t}$ and saving $B_{t}$ to maximize the utility function in (1) subject to the sequence of budget constraints

$$
C_{t}+\frac{B_{t}}{P_{t} R_{t}}=\frac{B_{t-1}}{P_{t}}+w_{t} N_{t}+\phi\left(1-N_{t}\right)+d_{t}, \quad \forall t \geq 0,
$$

where $P_{t}$ denotes the price level, $B_{t}$ denotes the household's holdings of a nominal risk-free bond, $R_{t}$ denotes the nominal interest rate, $w_{t}$ denotes the real wage rate, $\phi$ denotes an unemployment benefit, $d_{t}$ denotes profit income from the household's ownership of intermediate goods producers and of retailers.

Optimal bond-holding decisions result in the intertemporal Euler equation

$$
1=\mathrm{E}_{t} \beta \gamma_{a, t+1} \frac{\Lambda_{t+1}}{\Lambda_{t}} \frac{R_{t}}{\pi_{t+1}}
$$

where $\Lambda_{t}=\frac{1}{C_{t}}$ denotes the marginal utility of consumption and $\pi_{t} \equiv \frac{P_{t}}{P_{t-1}}$ denotes the inflation rate.

III.2. The aggregation sector. Denote by $Y_{t}$ the final consumption good, which is a basket of differentiated retail goods. Denote by $Y_{t}(j)$ a type $j$ retail good for $j \in[0,1]$. We assume that

$$
Y_{t}=\left(\int_{0}^{1} Y_{t}(j)^{\frac{\eta-1}{\eta}}\right)^{\frac{\eta}{\eta-1}}
$$

where $\eta>1$ denotes the elasticity of substitution between differentiated products.

Expenditure minimizing implies that demand for a type $j$ retail good is inversely related to the relative price, with the demand schedule given by

$$
Y_{t}^{d}(j)=\left(\frac{P_{t}(j)}{P_{t}}\right)^{-\eta} Y_{t}
$$

where $Y_{t}^{d}(j)$ and $P_{t}(j)$ denote the demand for and the price of retail good of type $j$, respectively. The price index $P_{t}$ is related to the individual prices $P_{t}(j)$ through the relation

$$
P_{t}=\left(\int_{0}^{1} P_{t}(j)^{\frac{1}{1-\eta}}\right)^{1-\eta} .
$$


III.3. The retail goods producers. There is a continuum of retail goods producers, each producing a differentiated product using a homogeneous intermediate good as input. The production function of retail good of type $j \in[0,1]$ is given by

$$
Y_{t}(j)=X_{t}(j)
$$

where $X_{t}(j)$ is the input of intermediate goods used by retailer $j$ and $Y_{t}(j)$ is the output. The retail goods producers are price takers in the input market and monopolistic competitors in the product markets, where they set prices for their products, taking as given the demand schedule in equation (7) and the price index in equation(8).

Price adjustments are subject to the quadratic cost

$$
\frac{\Omega_{p}}{2}\left(\frac{P_{t}(j)}{\pi P_{t-1}(j)}-1\right)^{2} Y_{t}
$$

where the parameter $\Omega_{p} \geq 0$ measures the cost of price adjustments and $\pi$ denotes the steady-state inflation rate. Here, we assume that price adjustment costs are in units of aggregate output.

A retail firm that produces good $j$ solves the profit-maximizing problem

$$
\max _{P_{t}(j)} \quad \mathrm{E}_{t} \sum_{i=0}^{\infty} \frac{\beta^{i} \Lambda_{t+i} A_{t+i}}{\Lambda_{t} A_{t}}\left[\left(\frac{P_{t+i}(j)}{P_{t+i}}-q_{t+i}\right) Y_{t+i}^{d}(j)-\frac{\Omega_{p}}{2}\left(\frac{P_{t+i}(j)}{\pi P_{t+i-1}(j)}-1\right)^{2} Y_{t+i}\right]
$$

where $q_{t+i}$ denotes the relative price of intermediate goods in period $t+i$. The optimal price-setting decision implies that, in a symmetric equilibrium with $P_{t}(j)=P_{t}$ for all $j$, we have

$$
q_{t}=\frac{\eta-1}{\eta}+\frac{\Omega_{p}}{\eta}\left[\frac{\pi_{t}}{\pi}\left(\frac{\pi_{t}}{\pi}-1\right)-\mathrm{E}_{t} \frac{\beta \gamma_{a, t+1} \Lambda_{t+1}}{\Lambda_{t}} \frac{Y_{t+1}}{Y_{t}} \frac{\pi_{t+1}}{\pi}\left(\frac{\pi_{t+1}}{\pi}-1\right)\right]
$$

Absent price adjustment costs (i.e., $\Omega_{p}=0$ ), the optimal pricing rule implies that real marginal cost $q_{t}$ equals the inverse of the steady-state markup.

III.4. The Labor Market. In the beginning of period $t$, there are $u_{t}$ unemployed workers searching for jobs and there are $v_{t}$ vacancies posted by firms. The matching technology is described by the Cobb-Douglas function

$$
m_{t}=\mu u_{t}^{\alpha} v_{t}^{1-\alpha}
$$

where $m_{t}$ denotes the number of successful matches and the parameter $\alpha \in(0,1)$ denotes the elasticity of job matches with respect to the number of searching workers. The term $\mu$ scales the matching efficiency. 
The probability that an open vacancy is matched with a searching worker (or the job filling rate) is given by

$$
q_{t}^{v}=\frac{m_{t}}{v_{t}} .
$$

The probability that an unemployed and searching worker is matched with an open vacancy (or the job finding rate) is given by

$$
q_{t}^{u}=\frac{m_{t}}{u_{t}} .
$$

In the beginning of period $t$, there are $N_{t-1}$ workers. A fraction $\rho$ of these workers lose their jobs. Thus, the number of workers who survive the job separation is $(1-\rho) N_{t-1}$. At the same time, $m_{t}$ new matches are formed. Following the timing assumption in Blanchard and Galí (2010), we assume that new hires start working in the period they are hired. Thus, aggregate employment in period $t$ evolves according to

$$
N_{t}=(1-\rho) N_{t-1}+m_{t} .
$$

With a fraction $\rho$ of employed workers separated from their jobs, the number of unemployed workers searching for jobs in period $t$ is given by

$$
u_{t}=1-(1-\rho) N_{t-1} .
$$

Following Blanchard and Galí (2010), we assume full participation and define the unemployment rate as the fraction of the population who are left without a job after hiring takes place in period $t$. Thus, the unemployment rate is given by

$$
U_{t}=u_{t}-m_{t}=1-N_{t} .
$$

III.5. The firms (intermediate good producers). A firm can produce only if it can successfully match with a worker. The production function for a firm with one worker is given by

$$
x_{t}=Z_{t},
$$

where $x_{t}$ is output and $Z_{t}$ is an aggregate technology shock. The technology shock follows the stochastic process

$$
\ln Z_{t}=\left(1-\rho_{z}\right) \ln Z+\rho_{z} \ln Z_{t-1}+\sigma_{z t} \varepsilon_{z t} .
$$

The parameter $\rho_{z} \in(-1,1)$ measures the persistence of the technology shock. The term $\varepsilon_{z t}$ is an i.i.d. innovation to the technology shock and is a standard normal process. The term $\sigma_{z t}$ is a time-varying standard deviation of the innovation and we interpret it as a technology uncertainty shock. We assume that the technology uncertainty shock follows the stationary stochastic process

$$
\ln \sigma_{z t}=\left(1-\rho_{\sigma_{z}}\right) \ln \sigma_{z}+\rho_{\sigma_{z}} \ln \sigma_{z, t-1}+\sigma_{\sigma_{z}} \varepsilon_{\sigma_{z}, t},
$$


where the parameter $\rho_{\sigma_{z}} \in(-1,1)$ measures the persistence of the technology uncertainty, the term $\varepsilon_{\sigma_{z}, t}$ denotes the innovation to the technology uncertainty and is a standard normal process, and the parameter $\sigma_{\sigma_{z}}>0$ is the standard deviation of the innovation.

If a firm finds a match, it obtains a flow profit in the current period after paying the worker. In the next period, if the match survives (with probability $1-\rho$ ), the firm continues; if the match breaks down (with probability $\rho$ ), the firm posts a new job vacancy at a fixed cost $\kappa$, with the value $V_{t+1}$. The value of a firm with a match is therefore given by the Bellman equation

$$
J_{t}^{F}=\left(1-\tau_{t}\right)\left(q_{t} Z_{t}-w_{t}\right)+E_{t} \frac{\beta \gamma_{a, t+1} \Lambda_{t+1}}{\Lambda_{t}}\left[(1-\rho) J_{t+1}^{F}+\rho V_{t+1}\right],
$$

where $\tau_{t}$ denotes a tax rate on flow profits.

If the firm posts a new vacancy in period $t$, it $\operatorname{costs} \kappa$ units of final goods. The vacancy can be filled with probability $q_{t}^{v}$, in which case the firm obtains the value of the match. Otherwise, the vacancy remains unfilled and the firm goes into the next period with the value $V_{t+1}$. Thus, the value of an open vacancy is given by

$$
V_{t}=-\kappa+q_{t}^{v} J_{t}^{F}+E_{t} \frac{\beta \gamma_{a, t+1} \Lambda_{t+1}}{\Lambda_{t}}\left(1-q_{t}^{v}\right) V_{t+1} .
$$

Free entry implies that $V_{t}=0$, so that

$$
\kappa=q_{t}^{v} J_{t}^{F}
$$

Substituting equation (22) into equation (21), we obtain

$$
\frac{\kappa}{q_{t}^{v}}=\left(1-\tau_{t}\right)\left(q_{t} Z_{t}-w_{t}\right)+E_{t} \frac{\beta \gamma_{a, t+1} \Lambda_{t+1}}{\Lambda_{t}}(1-\rho) \frac{\kappa}{q_{t+1}^{v}} .
$$

III.6. Workers' value functions. If a worker is employed, he obtains an after-tax wage income and suffers a utility cost for working in period $t$. In period $t+1$, the match is dissolved with probability $\rho$ and the separated worker can find a new match with probability $q_{t+1}^{u}$. Thus, with probability $\rho\left(1-q_{t+1}^{u}\right)$, the worker who gets separated does not find a new job in period $t+1$ and thus enters the unemployment pool. Otherwise, the worker continues to be employed. The (marginal) value of an employed worker therefore satisfies the Bellman equation

$$
J_{t}^{W}=w_{t}-\frac{\chi}{\Lambda_{t}}+E_{t} \frac{\beta \gamma_{a, t+1} \Lambda_{t+1}}{\Lambda_{t}}\left\{\left[1-\rho\left(1-q_{t+1}^{u}\right)\right] J_{t+1}^{W}+\rho\left(1-q_{t+1}^{u}\right) J_{t+1}^{U}\right\},
$$

where $J_{t}^{U}$ denotes the value of an unemployed household member. If a worker is currently unemployed, then he obtains an unemployment benefit and can find a new job in period $t+1$ with probability $q_{t+1}^{u}$. Otherwise, he stays unemployed in that period. The value of an 
unemployed worker thus satisfies the Bellman equation

$$
J_{t}^{U}=\phi+E_{t} \frac{\beta \gamma_{a, t+1} \Lambda_{t+1}}{\Lambda_{t}}\left[q_{t+1}^{u} J_{t+1}^{W}+\left(1-q_{t+1}^{u}\right) J_{t+1}^{U}\right] .
$$

III.7. The Nash bargaining wage. Firms and workers bargain over wages. The Nash bargaining problem is given by

$$
\max _{w_{t}}\left(J_{t}^{W}-J_{t}^{U}\right)^{b}\left(J_{t}^{F}\right)^{1-b}
$$

where $b \in(0,1)$ represents the bargaining weight for workers.

Define the total surplus as

$$
S_{t}=J_{t}^{F}+J_{t}^{W}-J_{t}^{U}
$$

Then the bargaining solution is given by

$$
J_{t}^{F}=(1-b) S_{t}, \quad J_{t}^{W}-J_{t}^{U}=b S_{t} .
$$

It then follows from equations (24) and (25) that

$$
b S_{t}=w_{t}^{N}-\phi-\frac{\chi}{\Lambda_{t}}+E_{t} \frac{\beta \gamma_{a, t+1} \Lambda_{t+1}}{\Lambda_{t}}\left[(1-\rho)\left(1-q_{t+1}^{u}\right) b S_{t+1}\right] .
$$

Given the bargaining surplus $S_{t}$, which itself is proportional to firm value $J_{t}^{F}$ (see the bargaining solution (28)), this last equation determines the Nash bargaining wage $w_{t}^{N}$.

If equilibrium real wage equals the Nash bargaining wage, then we can solve out an explicit expression for the Nash wage. Specifically, we use equations (22), (28), and (29) and impose $w_{t}=w_{t}^{N}$ to obtain

$$
w_{t}^{N}\left(1-b \tau_{t}\right)=(1-b)\left[\frac{\chi}{\Lambda_{t}}+\phi\right]+b\left[\left(1-\tau_{t}\right) q_{t} Z_{t}+\beta(1-\rho) E_{t} \frac{\beta \gamma_{a, t+1} \Lambda_{t+1}}{\Lambda_{t}} \frac{\kappa v_{t+1}}{u_{t+1}}\right] .
$$

In this case, the Nash bargaining wage (adjusted for taxes) is a weighted average of the worker's reservation value and the firm's productive value of a job match. By forming a match, the worker incurs a utility cost of working and foregoes unemployment benefits. By employing a worker, the firm receives the marginal product from labor (net of taxes) in the current period and saves the vacancy cost from the next period.

III.8. Wage Rigidity. In general, however, equilibrium real wage may be different from the Nash bargaining solution. Indeed, Hall (2005a) points out that real wage rigidity is important to generate empirically reasonable volatilities of vacancies and unemployment.

There are several ways to formalize real wage rigidity (Hall, 2005b; Gertler and Trigari, 2009; Blanchard and Galí, 2010). We follow the literature and consider real wage rigidity by assuming that the real wage is a geometrically weighted average of the Nash bargaining wage and the last-period realized wage. In particular, we consider the wage rule

$$
w_{t}=w_{t-1}^{\gamma}\left(w_{t}^{N}\right)^{1-\gamma},
$$


where $\gamma \in(0,1)$ represents the degree of real wage rigidity. ${ }^{12}$

III.9. Government policy. The government finances exogenous spending $G_{t}$ and unemployment benefit payments $\phi$ through profit taxes. We assume that the government balances the budget in each period so that

$$
G_{t}+\phi\left(1-N_{t}\right)=\tau_{t}\left(q_{t} Z_{t}-w_{t}\right) N_{t}
$$

The tax rate $\tau_{t}$ is adjusted endogenously to finance the exogenous spending $G_{t}$. We further assume that $G_{t}$ follows the stationary stochastic process

$$
\ln G_{t}=\left(1-\rho_{g}\right) \ln G+\rho_{g} \ln G_{t-1}+\sigma_{g} \varepsilon_{g t},
$$

where $\rho_{g} \in(-1,1)$ is the persistence parameter, the innovation $\varepsilon_{g t}$ is an i.i.d. standard normal process, and $\sigma_{g}$ is the time-varying standard deviation of the innovation. We interpret $\sigma_{g t}$ as an uncertainty shock to government spending.

The government spending uncertainty shock follows the stationary stochastic process

$$
\ln \sigma_{g t}=\left(1-\rho_{\sigma_{g}}\right) \ln \sigma_{g}+\rho_{\sigma_{g}} \ln \sigma_{g, t-1}+\sigma_{\sigma_{g}} \varepsilon_{\sigma_{g}, t},
$$

where the parameter $\rho_{\sigma_{g}} \in(-1,1)$ measures the persistence of the uncertainty shock to government spending, the term $\varepsilon_{\sigma_{g}, t}$ denotes the innovation to the uncertainty shock and is a standard normal process, and the parameter $\sigma_{\sigma_{g}}>0$ is the standard deviation of the innovation.

The monetary authority conducts monetary policy by following the Taylor rule

$$
R_{t}=r \pi^{*}\left(\frac{\pi_{t}}{\pi^{*}}\right)^{\phi_{\pi}}\left(\frac{Y_{t}}{Y}\right)^{\phi_{y}}
$$

where the parameter $\phi_{\pi}$ determines the aggressiveness of monetary policy against deviations of inflation from the target $\pi^{*}$ and $\phi_{y}$ determines the extent to which monetary policy accommodates output fluctuations. The parameter $r$ denotes the steady-state real interest rate (i.e., $r=\frac{R}{\pi}$ ).

III.10. Search equilibrium. In a search equilibrium, the markets for bonds, capital, final consumption goods, and intermediate goods all clear.

Since the aggregate supply of the nominal bond is zero, the bond market-clearing condition implies that

$$
B_{t}=0 \text {. }
$$

\footnotetext{
${ }^{12}$ We have examined other wage rules as those in Blanchard and Galí (2010) and we find that our results do not depend on the particular form of the wage rule.
} 
Goods market clearing implies the aggregate resource constraint

$$
C_{t}+\kappa v_{t}+\frac{\Omega_{p}}{2}\left(\frac{\pi_{t}}{\pi}-1\right)^{2} Y_{t}+G_{t}=Y_{t}
$$

where $Y_{t}$ denotes aggregate output of final goods.

Intermediate goods market clearing implies that

$$
Y_{t}=Z_{t} N_{t}
$$

\section{ECONOMic Implications FRom the DSGE MODEL}

To examine the macroeconomic effects of uncertainty shocks in our DSGE model, we calibrate the model parameters and simulate the model to examine impulse responses of macroeconomic variables to a few alternative sources of uncertainty shocks. We focus on the responses of unemployment, inflation, and the nominal interest rate following an uncertainty shock.

IV.1. Calibration. We calibrate the structural parameters to match several steady-state observations. For those structural parameters that do not affect the model's steady state, we calibrate their values to be consistent with other empirical studies in the literature. The structural parameters to be calibrated include $\beta$, the subjective discount factor; $\chi$, the disutility of working parameter; $\eta$, the elasticity of substitution between differentiated retail products; $\alpha$, the elasticity of matching with respect to searching workers; $\mu$, the matching efficiency parameter; $\rho$, the job separation rate; $\phi$, the flow unemployment benefits (in final consumption units); $\kappa$, the fixed cost of positing vacancies; $b$, the Nash bargaining weight; $\Omega_{p}$, the price adjustment cost parameter; $\pi$, the steady-state inflation rate (or inflation target); $\phi_{\pi}$, the Taylor-rule coefficient for inflation; and $\phi_{y}$, the Taylor-rule coefficient for output. In addition, we need to calibrate the parameters in the shock processes. The calibrated values of the model parameters are summarized in Table 1.

We set $\beta=0.99$, so that the model implies a steady-state real interest rate of 4 percent per annual. We set $\eta=10$ so that the average markup is about 11 percent, in line with the estimates obtained by Basu and Fernald (1997) and others. We set $\alpha=0.5$ following the literature (Blanchard and Galí, 2010; Gertler and Trigari, 2009). We set $\rho=0.1$, which is consistent with an average monthly job separation rate of about 3.4 percent as in the Job Openings and Labor Turnover Survey (JOLTS) for the period from 2001 to 2011. Following Hall and Milgrom (2008), we set $\phi=0.25$ so that the unemployment benefit is about 25 percent of normal earnings. We set $b=0.5$ following the literature.

We choose the value of the vacancy cost parameter $\kappa$ so that, in the steady state, the total cost of posting vacancies is about 2 percent of gross output. To assign a value of $\kappa$ then requires knowledge of the steady-state number of vacancies $v$ and the steady-state level 
of output $Y$. We calibrate the value of $v$ such that the steady-state vacancy filling rate is $q^{v}=0.7$ and the steady-state unemployment rate $U$ is 6 percent, as in den Haan, Ramey, and Watson (2000). Given the steady-state value of the job separation rate $\rho=0.1$, we obtain $m=\rho N=0.094$. Thus, we have $v=\frac{m}{q^{v}}=\frac{0.094}{0.7}=0.134$. To obtain a value for $Y$, we use the aggregate production function that $Y=Z N$ and normalize the level of technology such that $Z=1$. This procedure yields a calibrated value of $\kappa=0.14$.

Given the steady-state values of $m, u$, and $v$, we use the matching function to obtain an average matching efficiency of $\mu=0.65$. To obtain a value for $\chi$, we solve the steady-state system so that $\chi$ is consistent with an unemployment rate of 6 percent. The process results in $\chi=0.46$. We set the real wage rigidity parameter to $\gamma=0.8$.

The price adjustment cost parameter $\Omega_{p}$ and the Taylor-rule parameters $\phi_{\pi}$ and $\phi_{y}$ do not affect the model's steady state. We calibrate these parameters to be consistent with empirical studies in the literature. We set $\Omega_{p}=112$ so that the slope of the Phillips curve in the model corresponds to that in a Calvo staggered price-setting model with four quarters of price contract duration.For the Taylor rule parameters, we set $\phi_{\pi}=1.5$ and $\phi_{y}=0.2$. We set $\pi=1.005$, so that the steady-state inflation rate is about 2 percent per year, corresponding to the Federal Reserve's implicit inflation objective.

The model does not provide information for the parameters in the exogenous shock processes. For purpose of illustration, we normalize the steady-state levels of the shocks such that $\gamma_{a}=1, Z=1$. We set $g=0.2$ so that the steady-state ratio of government spending to aggregate output is about 20 percent. For each of the three first-moment shocks, we set the standard deviation to $\sigma_{k}=0.01$ and the persistence parameter to $\rho_{k}=0.90$, for $k \in\{a, z, g\}$.

For each of the three second moment shocks, we set the standard deviation to $\sigma_{\sigma_{k}}=0.4$ and the persistence parameter to $\rho_{\sigma_{k}}=0.73$. These calibrated parameters are broadly consistent with the estimated uncertainty shock processes in our benchmark 4-variable VAR. Specifically, as shown in Figure 3, a one-standard deviation shock to consumer uncertainty leads to a rise in the measured uncertainty of about 1.36 percentage points, representing about a 40 percent increase in the level of uncertainty relative to the sample mean (the sample mean of consumer uncertainty is about 3.35 percentage points). The VAR model also shows that the measured uncertainty falls to a level about 30 percent of its peak in about 12 months, suggesting that, if the uncertainty shock is approximated by an $\operatorname{AR}(1)$ process - as we assume in the model, then the persistence parameter should be about 0.9 at monthly frequencies (i.e., $0.9^{12} \approx 0.3$ ). In our quarterly model, this implies a value of the persistence parameter of about 0.73 (i.e., $0.9^{3}=0.73$ ).

IV.2. Macroeconomic effects of uncertainty shocks. We solve the model using third order approximations around the steady state. We then compute the impulse responses 
following an uncertainty shock. ${ }^{13}$ We consider three different types of uncertainty shocks: (1) preference uncertainty $\sigma_{a t}$; (2) technology uncertainty $\sigma_{z t}$; and (3) fiscal policy uncertainty $\sigma_{g t}$. We show that search frictions and nominal rigidities are both important for the transmission of uncertainty shocks.

The macroeconomic responses following the three different types of uncertainty shocks in our DSGE model are qualitatively similar. We thus focus on presenting the impulse responses following a technology uncertainty shock. ${ }^{14}$ Figures 12 shows that, an uncertainty shock to technology raises unemployment and lowers inflation and the nominal interest rate, as we observe in the data.

When prices are sticky, the recessionary effects of uncertainty are amplified through fluctuations in the relative price of intermediate goods (or equivalently, the markup in the retail sector). When prices are sticky, an increase in the level of uncertainty lowers the demand for both retail goods and intermediate goods. Thus, the relative price of intermediate goods falls, lowering firms' profits and the value of a filled vacancy. A decline in the real wage could have mitigated the fall in profits. But with real wage rigidities (as we assume in the model), this mitigating effect is dampened. Firms respond to the decline in profits and thus the value of a job match by posting fewer vacancies, making it more difficult for searching workers to find a match. Thus, unemployment rises. As more workers are unemployed, the household's income falls, reinforcing the initial decline in aggregate demand and in the relative price, leading to a multiplier that amplifies the effects of uncertainty shocks on macroeconomic activity.

A rise in the level of uncertainty and consequent reduction in aggregate demand not just raise the unemployment rate, but also lower the inflation rate. Under the Taylor rule, the central bank lowers the nominal interest rate to alleviate the contractionary and disinflationary effects of the uncertainty shock. Nonetheless, equilibrium unemployment still rises and equilibrium inflation still falls following a rise in uncertainty. Thus, the theory's predictions are in line with our empirical evidence that uncertainty shocks act like a negative aggregate demand shock.

IV.3. The importance of search frictions and nominal rigidities. We have shown that an uncertainty shock acts as a negative demand shocks that depresses aggregate activity. This effect is not unique to our model with search frictions and sticky prices. Similar

\footnotetext{
${ }^{13}$ To do so, we first simulate the model for large number of periods assuming no shocks hit the economy. Once we the economy converges to a stationary state, we introduce a one-standard deviation shock to uncertainty and compute the model's responses.

${ }^{14}$ The impulse responses following uncertainty shocks to preferences and to government spending are presented in the supplemental appendix.
} 
effects have also been found in the standard DSGE model without search frictions (Basu and Bundick, 2011; Fernández-Villaverde, Guerrón-Quintana, Kuester, and Rubio-Ramírez, 2011). We now illustrate how search frictions interact with nominal rigidities to amplify the aggregate demand effects of uncertainty shocks.

To illustrate the amplification mechanism for uncertainty shocks through labor search frictions, we display in Figure 13 the Beveridge curve (BC) and the job creation curve (JCC). The intersection of these two curves determines the equilibrium vacancy rate $v$ and unemployed searching workers $u .^{15}$

The Beveridge curve describes the inverse relation between $v$ and $u$ implied by the matching technology. In particular, the matching function (13) implies that

$$
v=\left(\frac{m}{\mu}\right)^{\frac{1}{1-\alpha}}\left(\frac{1}{u}\right)^{\frac{\alpha}{1-\alpha}} .
$$

This Beveridge curve relation also reveals that, for any given matching $m$ and the elasticity parameter $\alpha$, the vacancy rate $v$ is a convex function of the number of searching workers $u$.

The job creation curve describes the optimal vacancy posting decision in equation (22). It represents a positive relation between $v$ and $u$ for any given firm value $J^{F}$ and vacancy cost $\kappa$. In particular, the JCC is described by the relation

$$
v=\left(\frac{\mu J^{F}}{\kappa}\right)^{\frac{1}{\alpha}} u
$$

where we have used the definition of the vacancy filling rate $q^{v}=\frac{m}{v}$ and the matching function (13).

First, consider the labor market equilibrium in our benchmark model. Suppose the initial (steady-state) equilibrium is at point $A$ in Figure 13. As we have discussed in the previous section, an increase in uncertainty lowers the value of a job match (i.e., $J^{F}$ declines) through the aggregate demand channel and real wage rigidities amplify the decline in firm value. Thus, the JCC rotates downward, leading to a new equilibrium at point $B$, with a lower vacancy rate and a higher unemployment rate. This downward rotation of the JCC predicted by the theory is consistent with the empirical responses of the labor market tightness (i.e., the $\mathrm{v}-\mathrm{u}$ ratio) shown in Figure 10.

Now, consider a counterfactual economy with a smaller cost of vacancy posting $\kappa$. In such an economy, search frictions are less important than in our benchmark economy. If vacancy costs are smaller, firms will post more vacancies, implying a higher job finding rate for a

\footnotetext{
${ }^{15}$ Under the timing of our model, $u$ is the number of unemployed workers who are searching for jobs. Total unemployment is the fraction of searching workers who remain without a job after matching occurs (i.e., $U=u-m$; see equation (18)).
} 
searching worker. ${ }^{16}$ From equation (40), a lower value of $\kappa$ implies a higher value of $v$ for any given $u$. Thus, the job creation curve (the solid black line denoted by $J C C^{\prime}$ ) is steeper than that in the benchmark economy (the solid blue line denoted by JCC). Accordingly, the labor-market equilibrium implies a higher vacancy rate and a lower unemployment rate (point $A^{\prime}$ ). When the level of uncertainty increases, the job creation curve rotates downward along the Beveridge curve, reaching the new equilibrium at point $B^{\prime}$. As in the benchmark model, the increase in uncertainty lowers the vacancy rate and raises the unemployment rate. But because the Beveridge curve represents a convex relation between $v$ and $u$, the increase in unemployment in this counterfactual economy with a lower vacancy cost is smaller than that in the benchmark economy.

The quantitative importance of having both search frictions and nominal rigidities is illustrated in Figure 14. The figure shows the impulse responses of unemployment following a technology uncertainty shock. The solid line indicates the impulse responses of unemployment in the calibrated benchmark DSGE model with both search frictions and nominal rigidities. The dashed line shows the impulse responses in the flexible-price model (with $\Omega_{p}=0$ imposed). The dashed and dotted line shows the impulse responses in a model that is otherwise identical to the benchmark model except that the vacancy cost parameter $\kappa$ is set to a smaller value (0.05 instead of the benchmark calibration of 0.14 ).

When prices are flexible, a technology uncertainty shock leads to an increase in unemployment, although the magnitude of the increase is about one-sixth as large as that in the benchmark model with sticky prices (see the dashed line in the figure). This finding

The figure reveals that the response of unemployment to a technology uncertainty shock in the benchmark model is about 3 times as large as that in a model with a smaller magnitude of search frictions and about 6 times as large as that in a model with flexible prices. These comparisons reveal that, absent either search frictions or nominal rigidities, the effects of uncertainty shocks on unemployment would be substantially muted.

\section{Conclusion}

In this paper, we study the macroeconomic effects of uncertainty shocks and show that uncertainty shocks act like aggregate demand shocks both in the data and in a DSGE model with search frictions and sticky prices.

\footnotetext{
${ }^{16}$ Our model does not completely nest the standard RBC model with a spot labor market. In the extreme case with $\kappa=0$, the vacancy-posting decision problem is not well defined.
} 
Using two clean measures of uncertainty from survey data, we have documented robust evidence that an increase in the level of uncertainty leads to a rise in unemployment and declines in inflation and the nominal interest rate. This result is robust to alternative measures of uncertainty, alternative identification strategies, and alternative model specifications.

To help understand the transmission mechanisms of uncertainty shocks, we present a DSGE model with search frictions and nominal rigidities. We show that interactions between search frictions and nominal rigidities help significantly amplify the macroeconomic effects of uncertainty shocks. Absent either frictions, the recessionary effects of an uncertainty shock would be substantially muted. Consistent with the evidence, our DSGE model predicts that an uncertainty shock - regardless of its source - raises unemployment and lowers inflation and the nominal interest rate, and thus acts like a negative aggregate demand shock.

To highlight the aggregate demand effects of uncertainty shocks, we have focused on a stylized model that abstracts from some realistic and potentially important features of the actual economy. For example, the model does not have endogenous capital accumulation and is thus not designed to studying the effects of uncertainty shocks on business investment. To the extent that investment adjustments are costly, investors are likely to cut back investment expenditures when they face higher levels of uncertainty. Thus, incorporating endogenous capital accumulation in our model with search frictions may have important implications for the quantitative magnitude of the responses of potential and equilibrium output. However, in light of several recent studies in the literature (Basu and Bundick, 2011; FernándezVillaverde, Guerrón-Quintana, Kuester, and Rubio-Ramírez, 2011), incorporating capital accumulation is unlikely to change the qualitative transmission mechanism of uncertainty shocks that we have identified in this paper.

In our model, uncertainty shocks raise equilibrium unemployment by lowering the value of job matches, thus reducing job creation. Meanwhile, we have assumed that the job separation rate is exogenous. Therefore, the responses of equilibrium vacancy and unemployment represent a movement along the downward-sloping Beveridge curve. A more realistic model should incorporate endogenous job separation along the lines of den Haan, Ramey, and Watson (2000) and Walsh (2005), which is likely to further strengthen the aggregate demand effects of uncertainty shocks that we have studied in this paper. This should prove a fruitful avenue that we intend to pursue in future research. 
TABLE 1. Parameter calibration

\begin{tabular}{lll}
\hline \hline Parameter & Description & value \\
\hline$\beta$ & Structural parameters & \\
$\chi \chi$ & Household's discount factor & 0.99 \\
$\eta$ & Scale of disutility of working & 0.38 \\
$\alpha$ & Elasticity of substitution between differentiated goods & 10 \\
$\mu$ & Share parameter in matching function & 0.50 \\
$\rho$ & Matching efficiency & 0.65 \\
$\phi$ & Job separation rate & 0.10 \\
$\kappa$ & Flow value of unemployment & 0.25 \\
$b$ & Vacancy cost & 0.14 \\
$\gamma$ & Nash bargaining weight & 0.5 \\
$\Omega_{p}$ & Real wage rigidity & 0.8 \\
$\pi$ & Price adjustment cost & 112 \\
$\phi_{\pi}$ & Steady-state inflation (or inflation target) & 1.005 \\
$\phi_{y}$ & Taylor-rule coefficient for inflation & 1.5 \\
\hline & Taylor-rule coefficient for output & 0.2 \\
\hline$\gamma_{a}$ & Shock parameters & \\
$Z$ & Average value of preference shock & 1 \\
$g$ & Average value of technology shock & 1 \\
$\rho_{k}$ & Average ratio of government spending to output & 0.2 \\
$\sigma_{k}$ & Persistence of first-moment shocks & 0.90 \\
$\rho_{\sigma_{k}}$ & Mean value of volatility of shock $k \in\left\{\gamma_{a}, z, g\right\}$ & 0.01 \\
$\sigma_{\sigma_{k}}$ & Persistence of uncertainty shock $\sigma_{k t}$ & 0.73 \\
\hline & Standard deviation of uncertainty shock $\sigma_{k t}$ & 0.4 \\
\hline
\end{tabular}




\section{Consumer Uncertainty vs VIX Index}

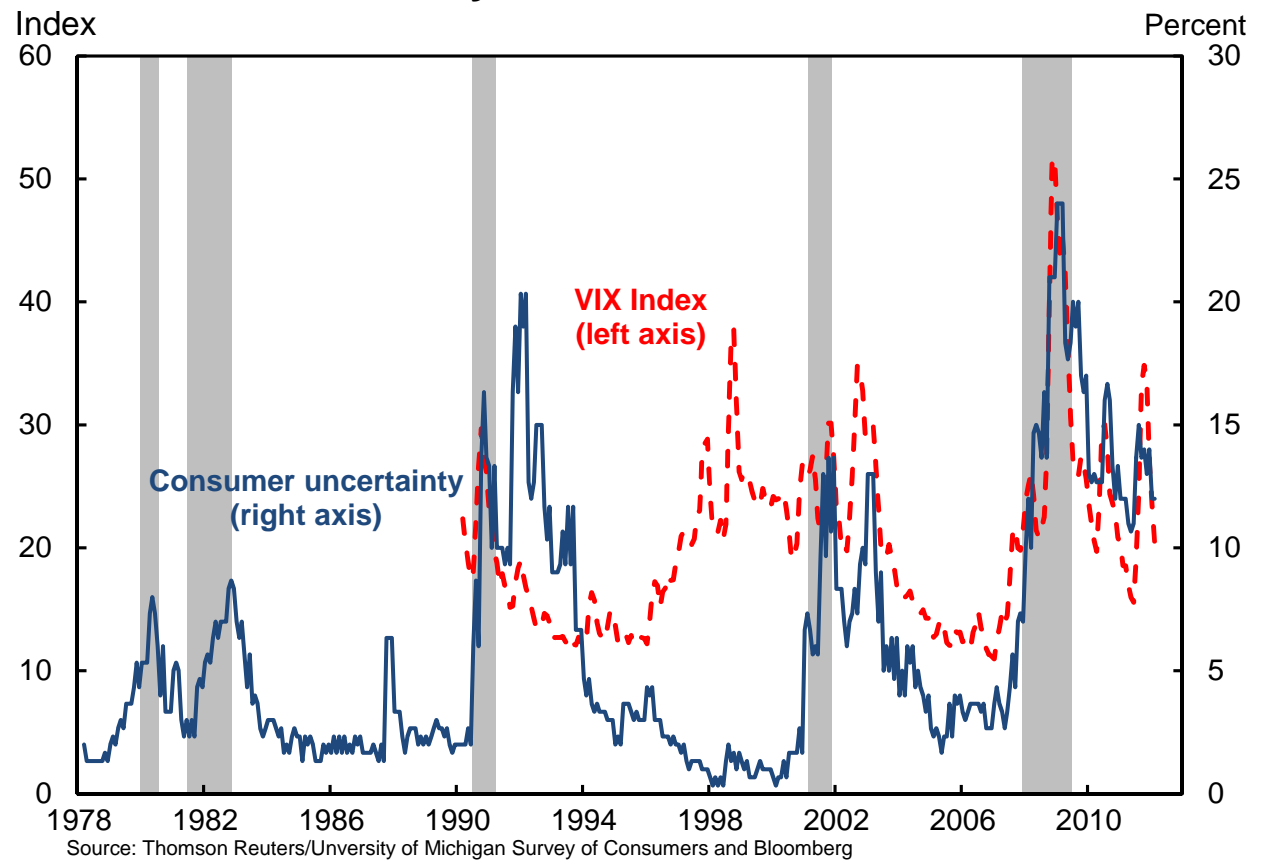

FiguRE 1. Consumers' perceived uncertainty from the Michigan Survey of Consumers in the United States versus the VIX index. The grey shaded areas indicate NBER recession dates in the United States. Data frequencies are monthly. Three-month moving averages are plotted. 


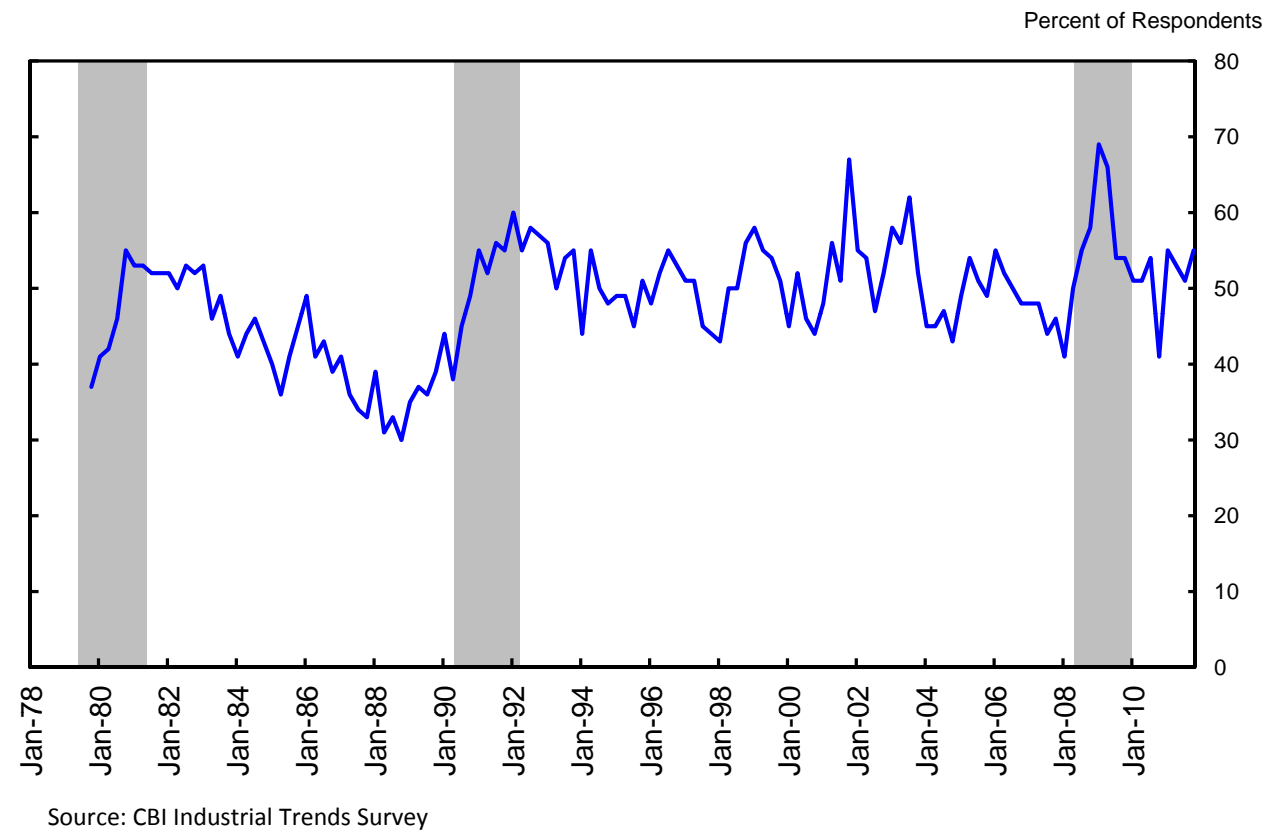

Figure 2. Firms' perceived uncertainty from the CBI Industrial Trends Survey in the United Kingdom. The grey shaded ares indicate recession dates in the United Kingdom. Data frequency is quarterly. 

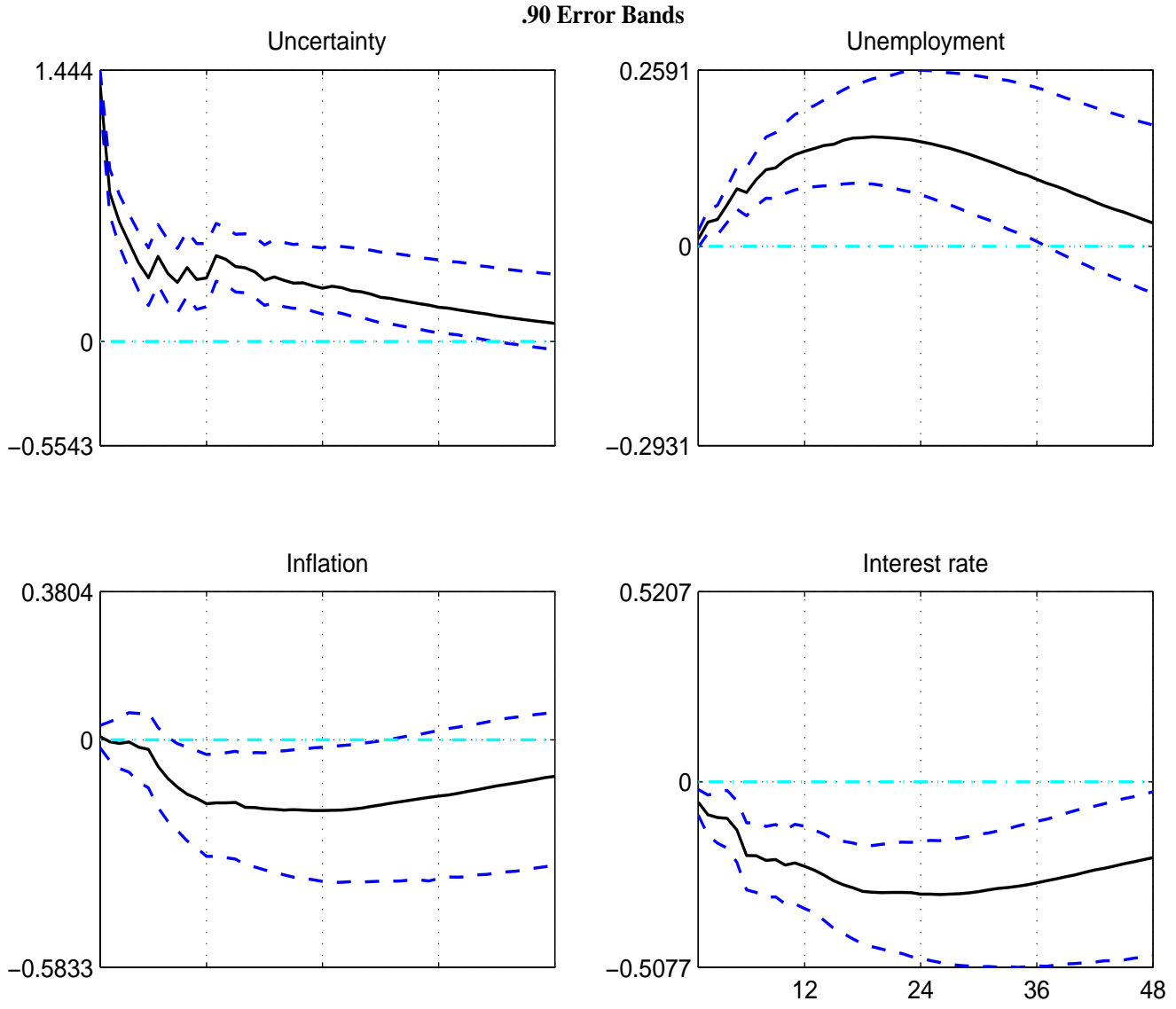

Figure 3. The effects of a one-standard deviation shock to perceived uncertainty in the Michigan Survey of Consumers: uncertainty measure ordered first. The solid lines represent median responses of the variables to a onestandard-deviation increase in the innovations to uncertainty. The dashed lines around each solid line represent the 90-percent confidence bands of the estimated median impulse responses. 

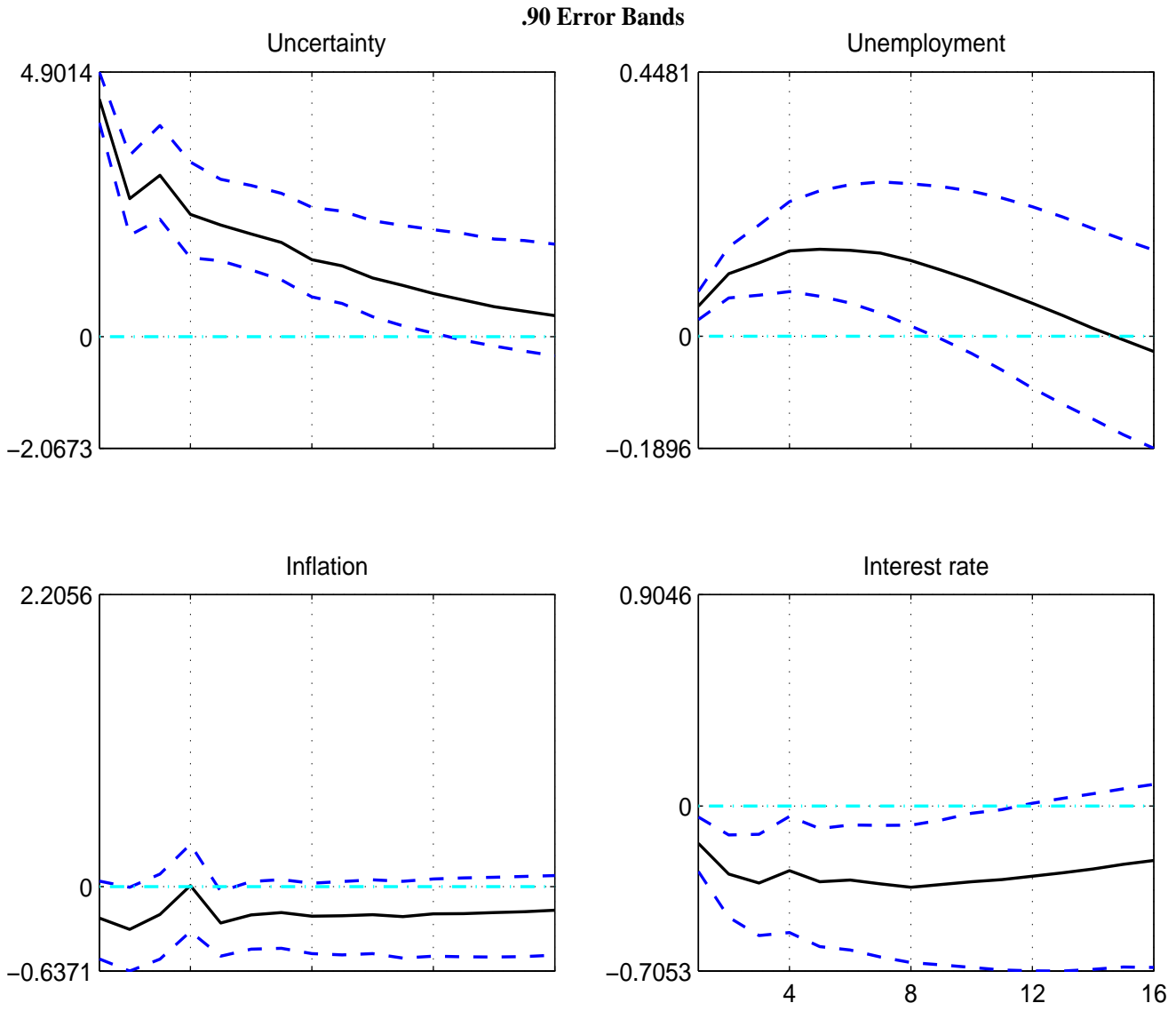

FiguRE 4. The effects of a one-standard deviation shock to perceived uncertainty in the CBI Industrial Trends Survey in the United Kingdom. The solid lines represent median responses of the variables to a one-standard-deviation increase in the innovations to uncertainty. The dashed lines around each solid line represent the 90-percent confidence bands of the estimated median impulse responses. 

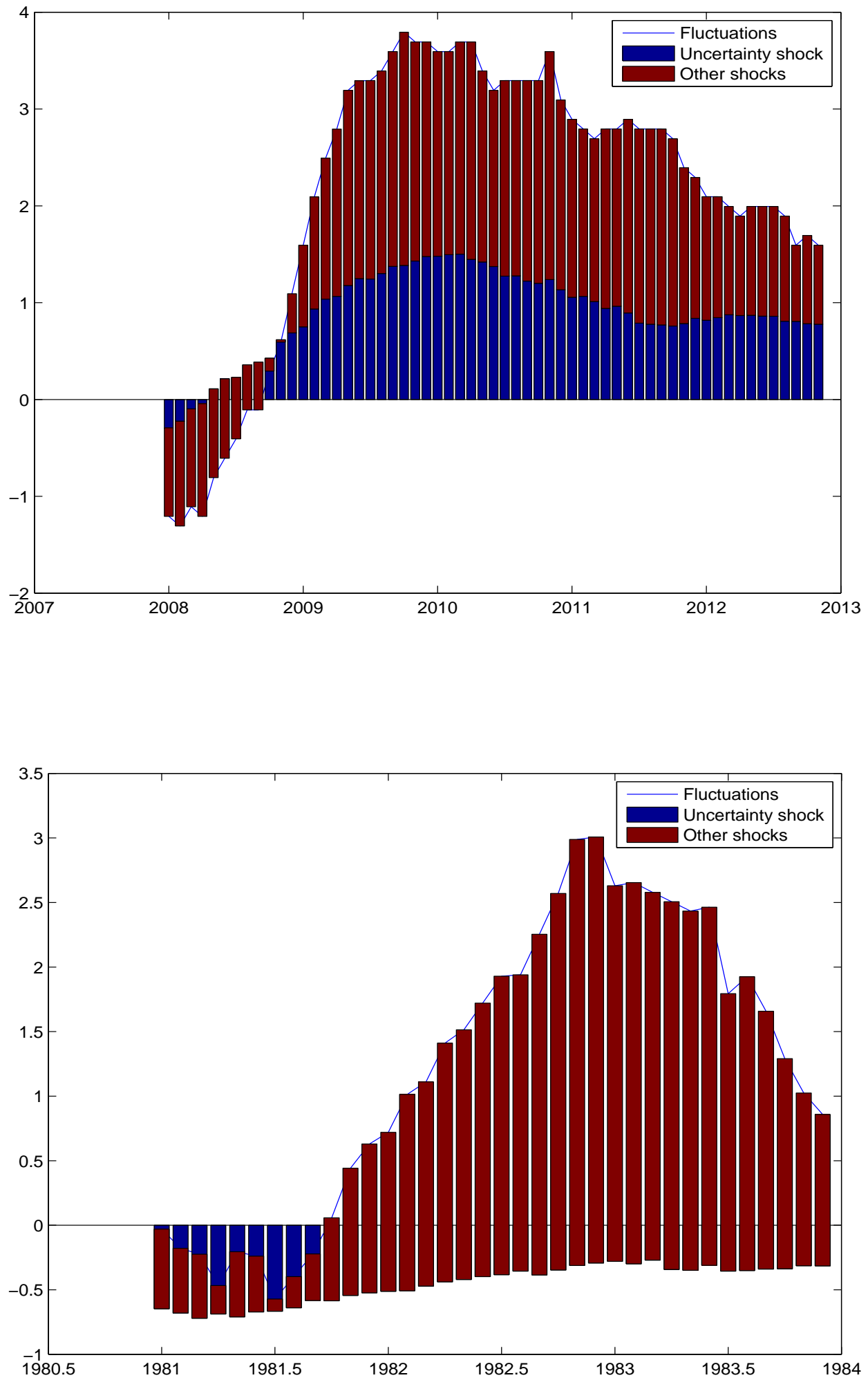

FiguRE 5. Historical decomposition. The figures show the contributions of uncertainty shocks to the increases in unemployment in the Great Recession and recovery (top panel) and in the 1981-82 recession (bottom panel). 

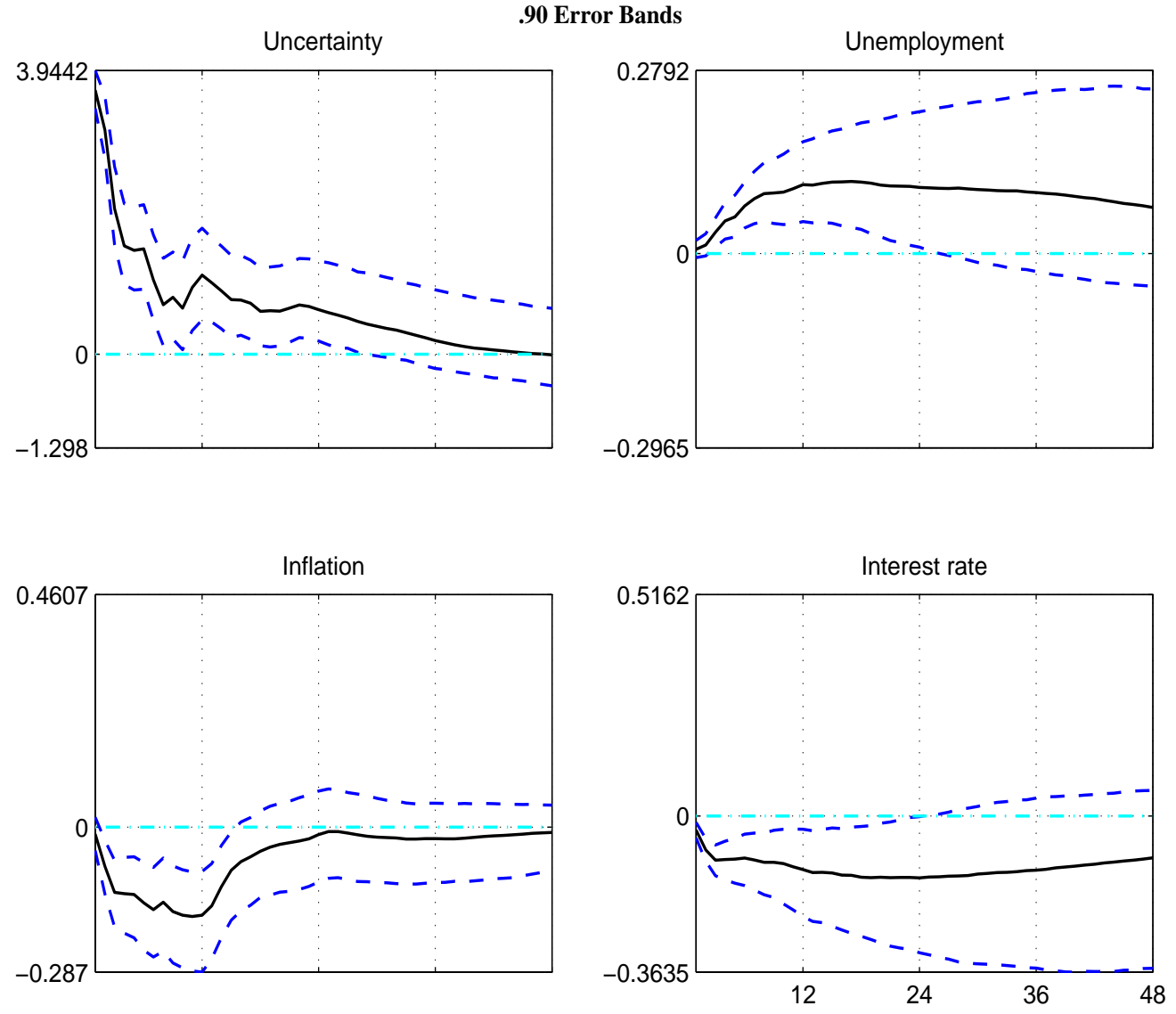

FiguRE 6. The effects of a one-standard deviation shock to the VIX index. The solid lines represent median responses of the variables to a one-standarddeviation increase in the innovations to uncertainty. The dashed lines around each solid line represent the 90-percent confidence bands of the estimated median impulse responses. 

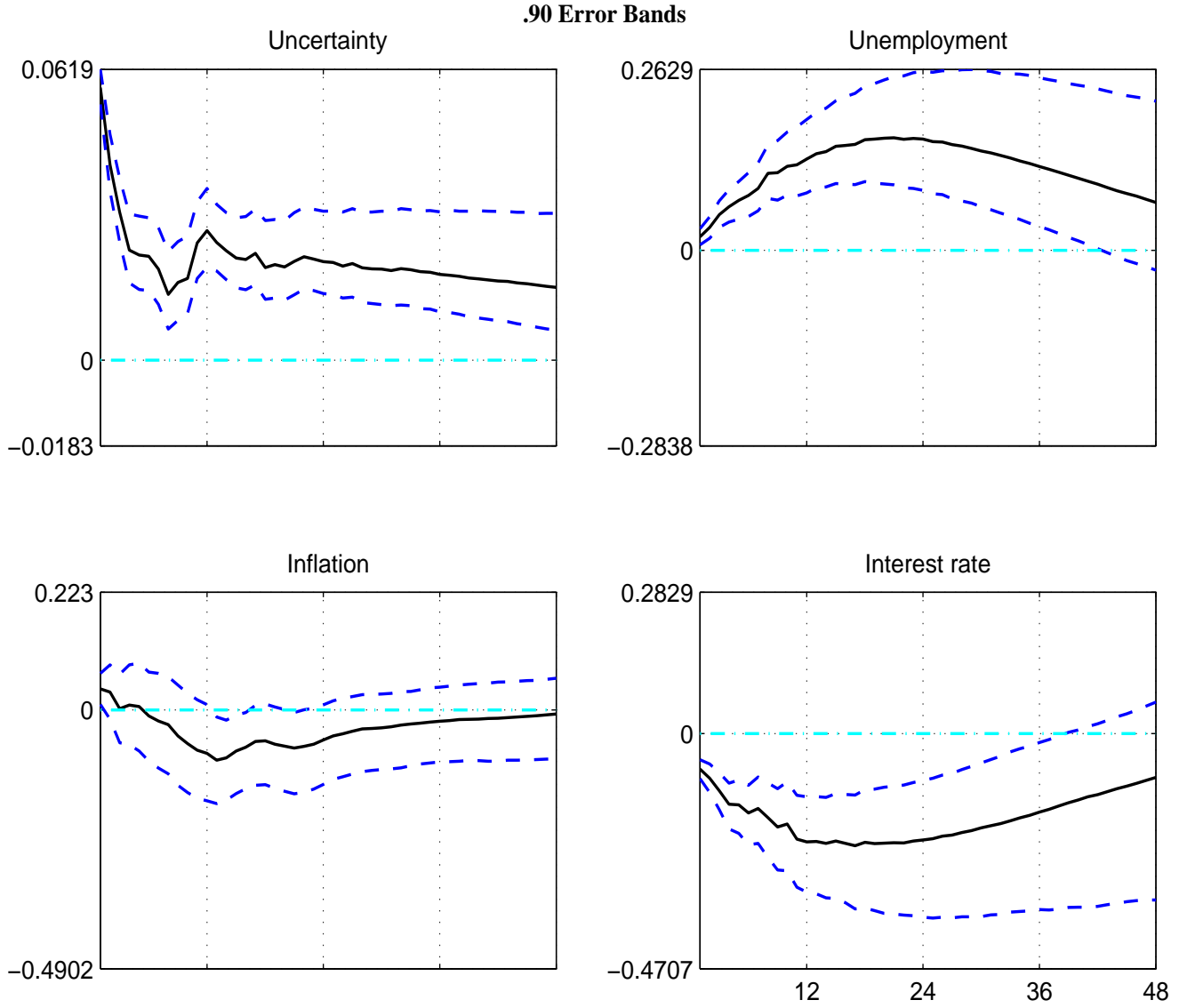

FiguRE 7. The effects of a one-standard deviation shock to policy uncertainty. The solid lines represent median responses of the variables to a one-standarddeviation increase in the innovations to uncertainty. The dashed lines around each solid line represent the 90-percent confidence bands of the estimated median impulse responses. 

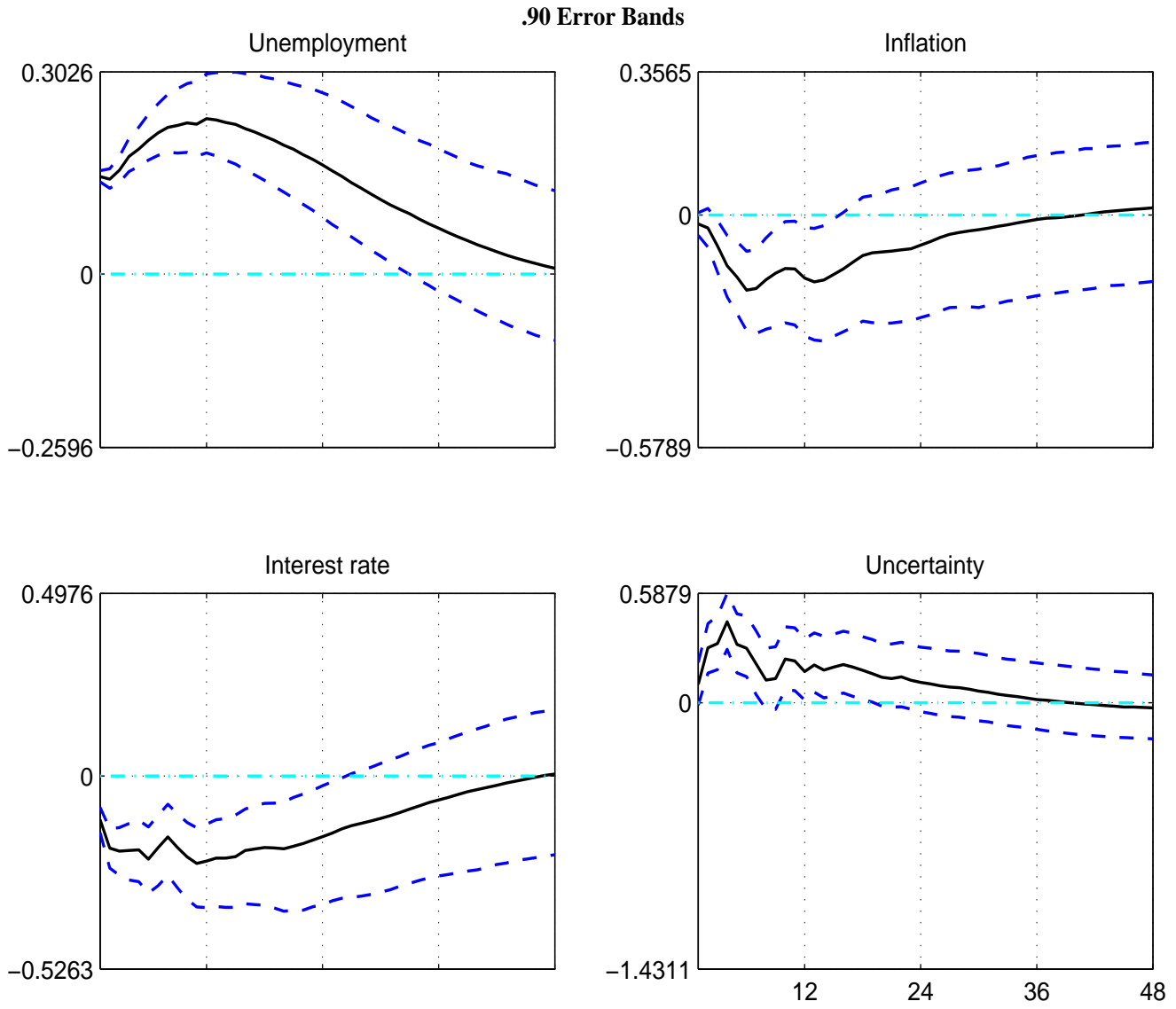

Figure 8. The effects of a one-standard deviation shock to perceived uncertainty in the Michigan Survey of Consumers: uncertainty measure ordered last. The solid lines represent median responses of the variables to a onestandard-deviation increase in the innovations to uncertainty. The dashed lines around each solid line represent the 90-percent confidence bands of the estimated median impulse responses. 


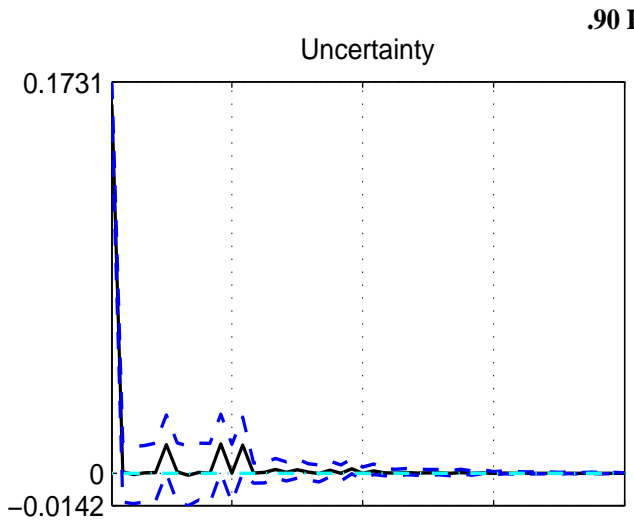

90 Error Bands
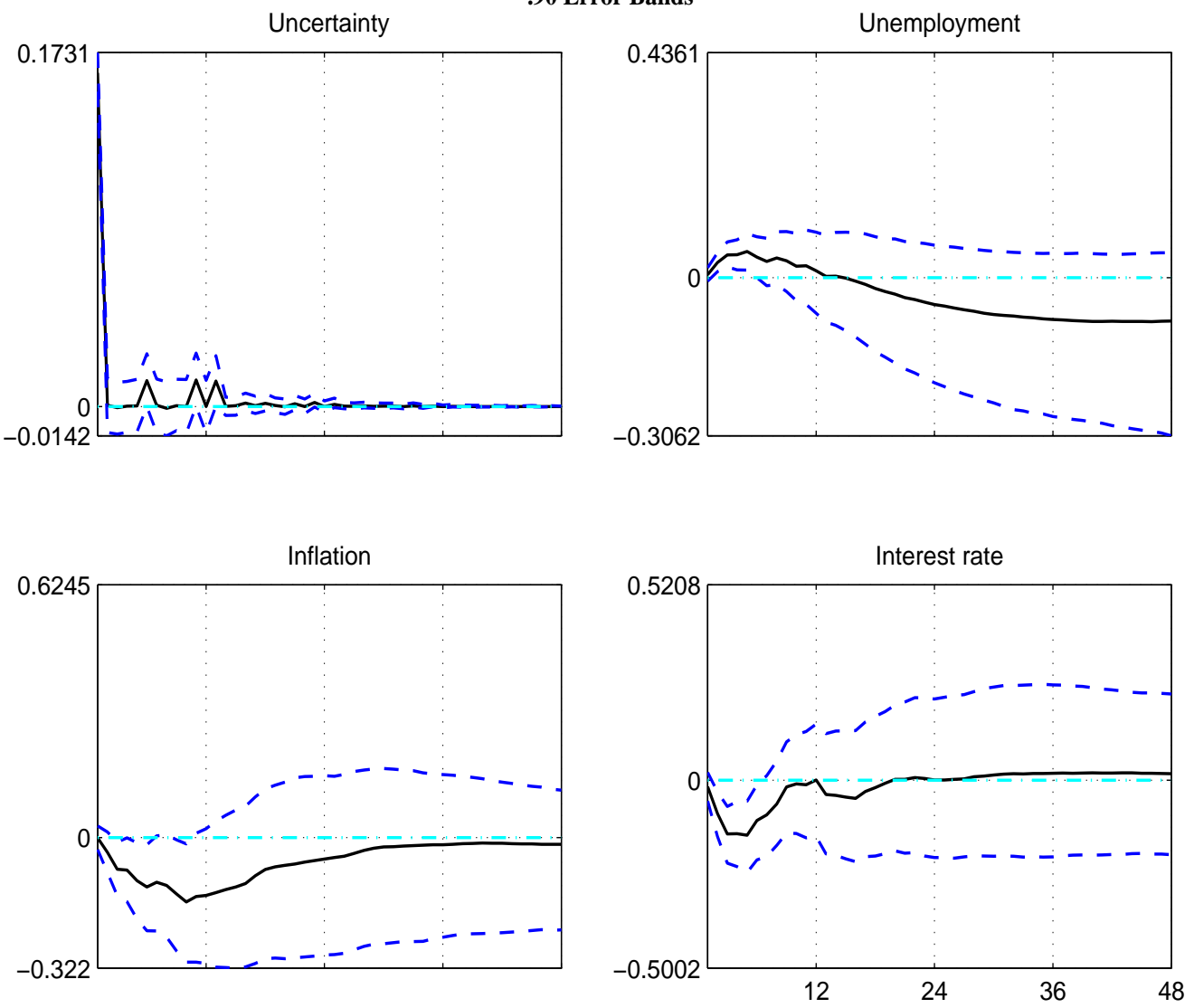

Figure 9. The effects of shock to uncertainty dummies. The solid lines represent median responses of the variables. The dashed lines around each solid line represent the 90-percent confidence bands of the estimated median impulse responses. 


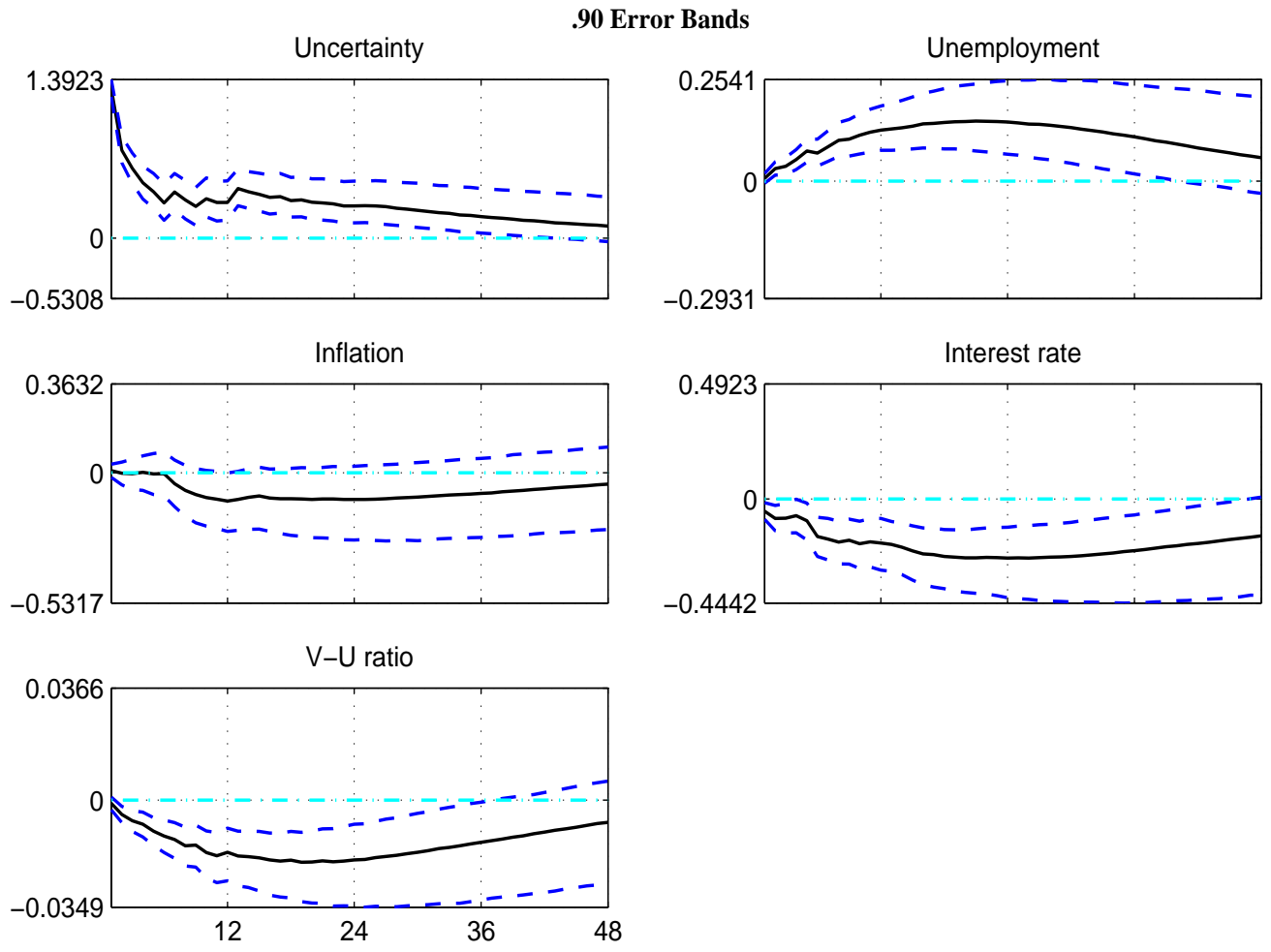

FiguRE 10. The effects of a one-standard deviation shock to perceived uncertainty in the Michigan Survey of Consumers in the VAR model augmented with the vacancy-unemployment ratio. The solid lines represent median responses of the variables to a one-standard-deviation increase in the innovations to uncertainty. The dashed lines around each solid line represent the 90-percent confidence bands of the estimated median impulse responses. 


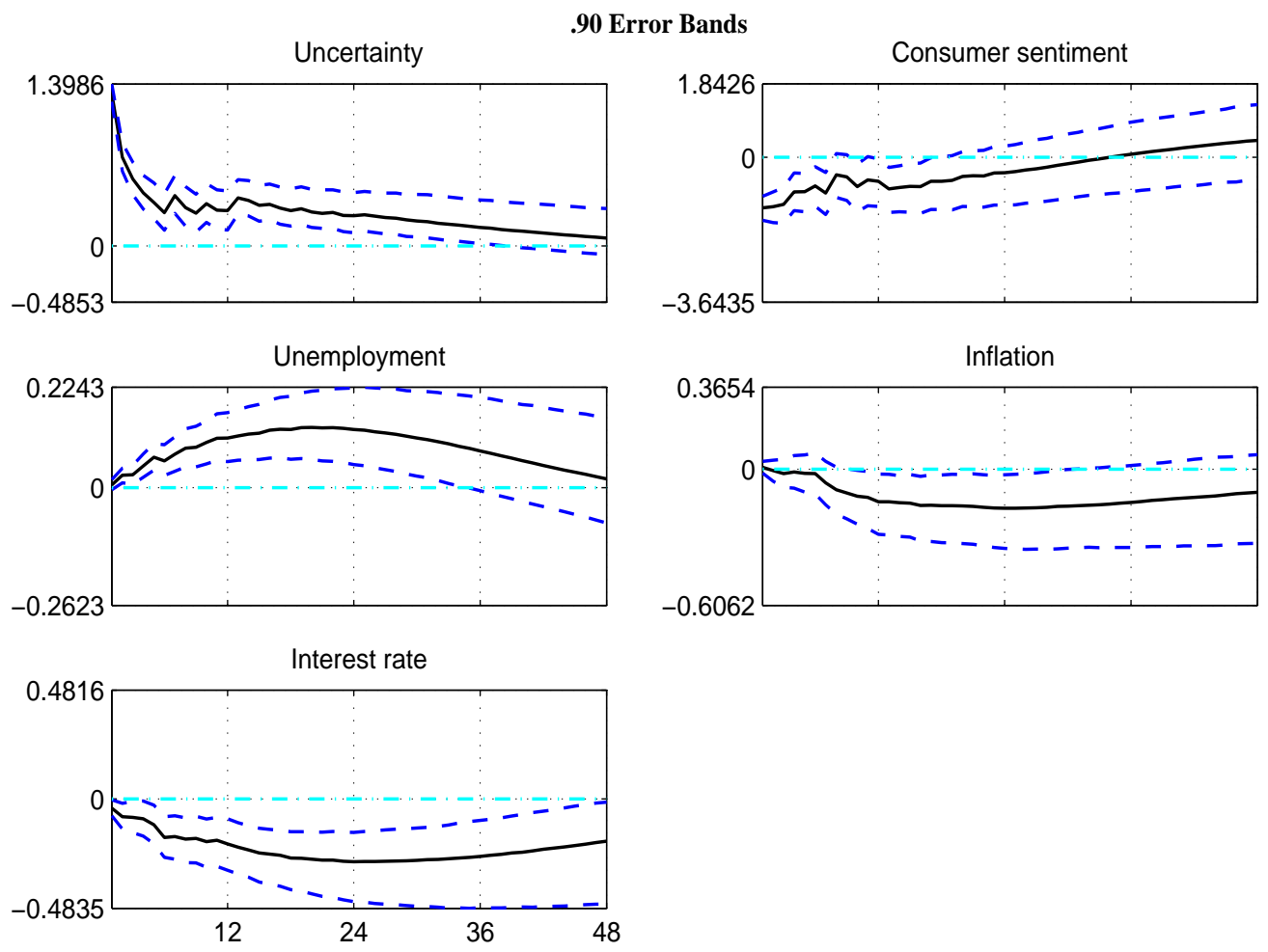

FiguRE 11. The effects of a one-standard deviation shock to consumers' perceived uncertainty from the Michigan Survey in the VAR model augmented with the consumer sentiment index (current conditions). The solid lines represent median responses of the variables to a one-standard-deviation increase in the innovations to uncertainty. The dashed lines around each solid line represent the 90-percent confidence bands of the estimated median impulse responses. 

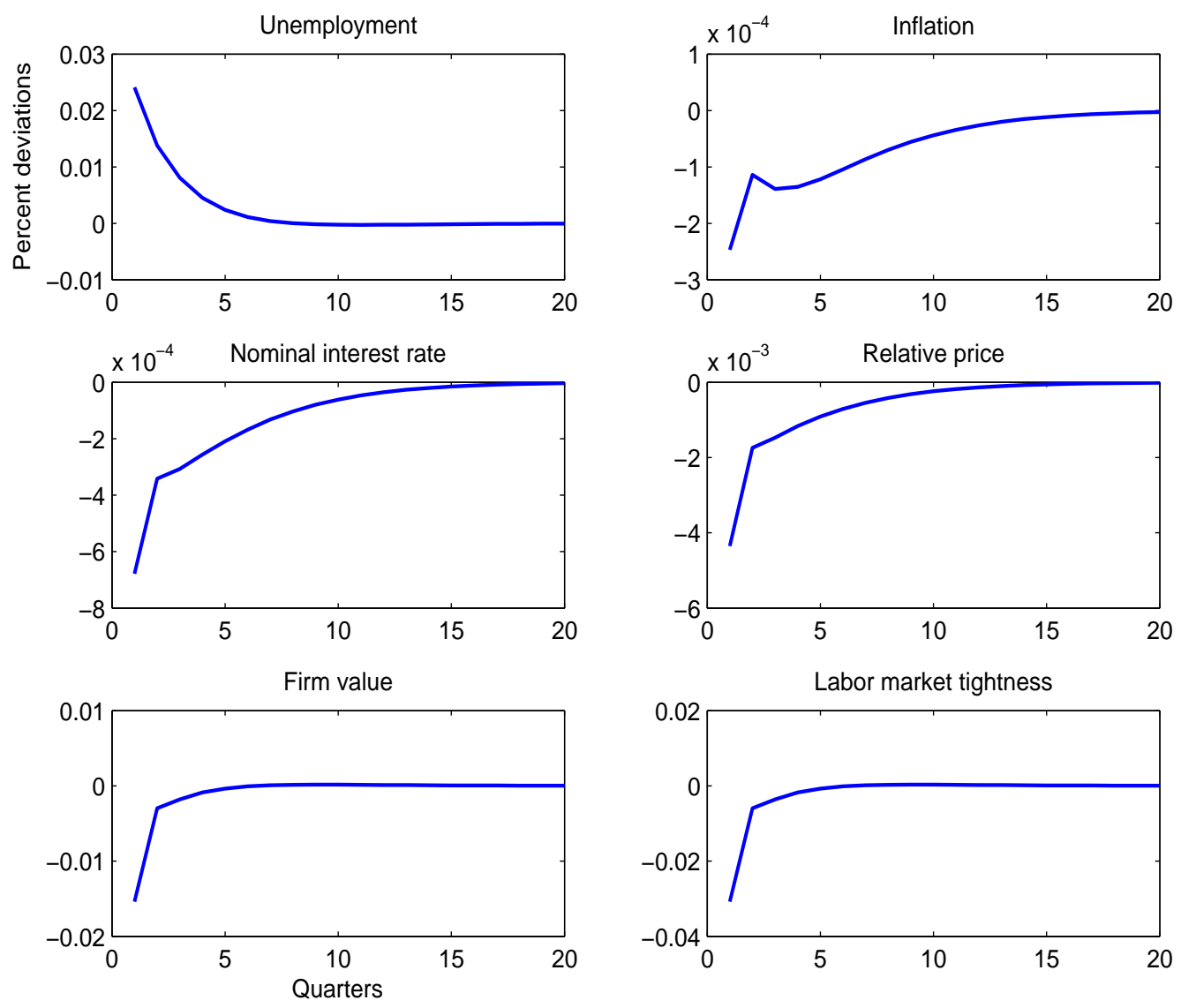

FiguRE 12. Impulse responses of macroeconomic variables to a technology uncertainty shock in the DSGE model with sticky prices. 


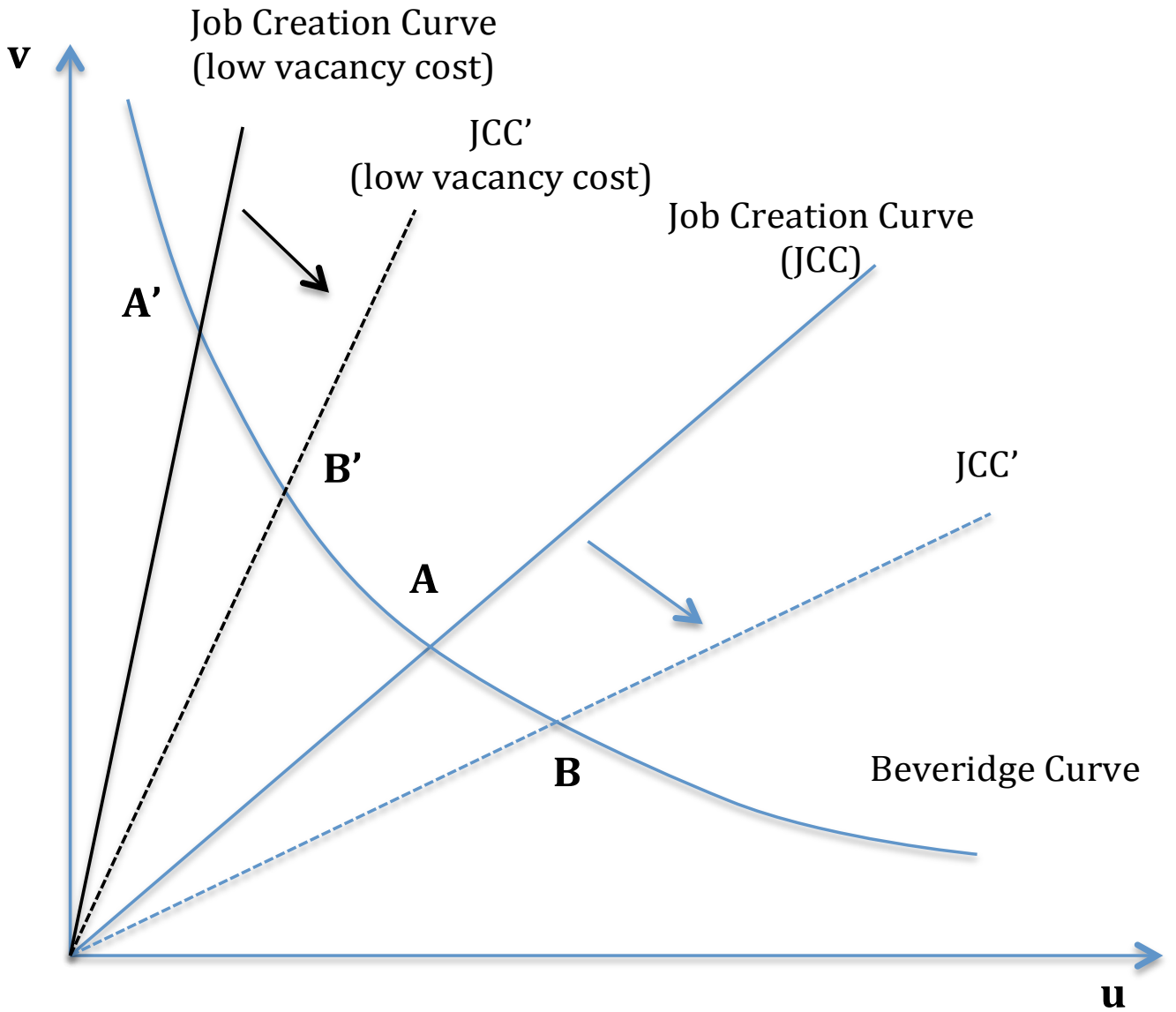

FIgURE 13. The amplification mechanism through labor market search frictions. 


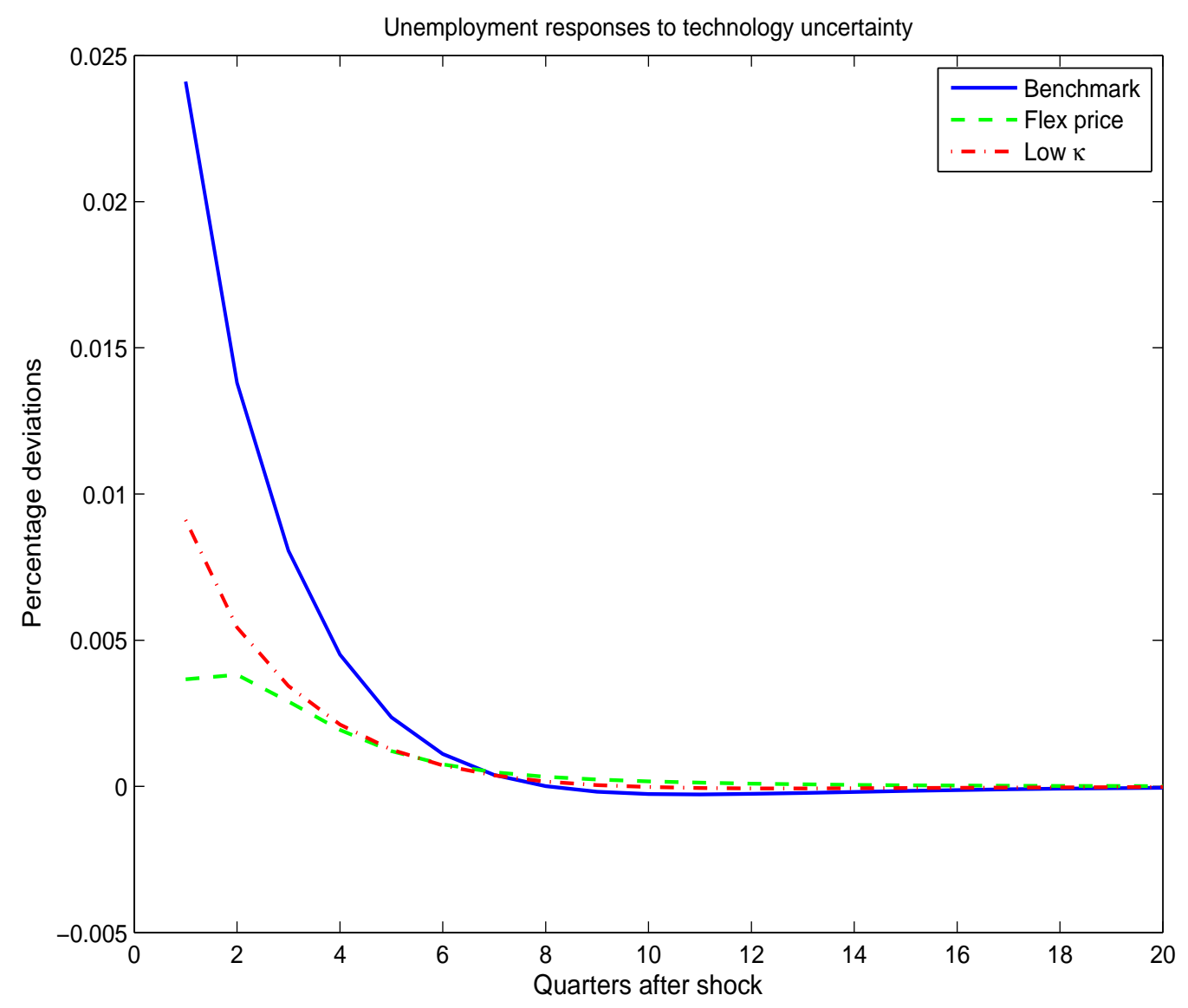

FIGURE 14. Impulse responses of unemployment to a technology uncertainty shock in the benchmark DSGE model ("Benchmark"), the flexible-price model ("Flex prices"), and a model with low vacancy costs ("Low $\kappa$ '). 


\section{REFERENCES}

Alexopoulos, M., And J. Cohen (2009): "Uncertain Times, Uncertain Measures," University of Toronto Department of Economics Working Paper 352.

Arellano, C., Y. Bai, and P. Kehoe (2011): "Financial Markets and Fluctuations in Uncertainty," Federal Reserve Bank of Minneapolis Research Department Staff Report.

Auerbach, A. J., And Y. Gorodnichenko (2012): "Measuring the Output Responses to Fiscal Policy," American Economic Journal: Economic Policy, 4, 1-27.

Bachmann, R., S. Elstner, and E. Sims (2011): "Uncertainty and Economic Activity: Evidence from Business Survey Data," University of Michigan Working Paper.

Bachmann, R., and G. Moscarini (2011): "Business Cycles and Endogenous Uncertainty," Yale University Working Paper.

Baker, S. R., N. Bloom, And S. J. Davis (2011): "Measuring Economic Policy Uncertainty," Stanford University Working Paper.

BARro, R. J. (2006): "Rare Disasters and Asset Markets in the Twentieth Century," Quarterly Journal of Economics, 121(3), 823-866.

Basu, S., And B. Bundick (2011): "Uncertainty Shocks in a Model of Effective Demand," Boston College Working Paper.

Basu, S., And J. G. Fernald (1997): "Returns to Scale in U.S. Production: Estimates and Implications," Journal of Political Economy, 105(2), 249-283.

Bernanke, B. S. (1983): "Irreversibility, Uncertainty, and Cyclical Investment," Quarterly Journal of Economics, 98(1), 85-106.

Bernanke, B. S., M. Gertler, and S. Gilchrist (1999): "The Financial Accelerator in a Quantitative Business Cycle Framework," in The Handbook of Macroeconomics, ed. by J. B. Taylor, and M. Woodford, pp. 1341-1393. Elsevier Science B.V., Amsterdam, North Holland.

Blanchard, O. J., And J. Galí (2010): "Labor Markets and Monetary Policy: A New Keynesian Model with Unemployment," American Economic Journal: Macroeconomics, 2, 1-30.

Bloom, N. (2009): "The Impact of Uncertainty Shocks," Econometrica, 77(3), 623-685.

Bloom, N., And J. Fernandez-Villaverde (2012): "The Macroeconomics of Uncertainty and Volatility," Unpublished working paper, Stanford University and University of Pennsylvania.

Bloom, N., M. Floetotto, N. Jaimovich, I. Saporta-Eksten, and S. J. Terry (2012): "Really Uncertain Business Cycles," NBER Working Paper18245.

Christiano, L., R. Motto, and M. Rostagno (2012): "Risk Shocks," Unpublished manuscript, Northwestern University. 
den Haan, W. J., G. Ramey, and J. Watson (2000): “Job Destruction and Propagation of Shocks," American Economic Review, 90, 482-498.

Diamond, P. A. (1982): “Aggregate Demand Management in Search Equilibrium," Journal of Political Economy, 90(5), 881-894.

Fernández-Villaverde, J., P. Guerrón-Quintana, K. Kuester, and J. RubioRAmírez (2011): "Fiscal Volatility Shocks and Economic Activity," University of Pennsylvania Working Paper.

Gabaix, X. (2012): "Variable Rare Disasters: An Exactly Solved Framework for Ten Puzzles in Macro-Finance," Quarterly Journal of Economics, 127(2), 645-700.

Gertler, M., And A. Trigari (2009): "Unemployment Fluctuations with Staggered Nash Wage Bargaining," Journal of Political Economy, 117(1), 38-86.

Gilchrist, S., J. W. Sim, And E. ZakrajSEK (2010): "Uncertainty, Financial Frictions, and Investment Dynamics," Boston University Working Paper.

Gourio, F. (2012): "Disaster Risk and Business Cycles," American Economic Review, $102(6), 2734-2766$.

Guiso, L., And G. PARIGi (1999): "Investment and Demand Uncertainty," Quarterly Journal of Economics, 114, 185-227.

Hall, R. E. (2005a): "Employment Fluctuations with Equilibrium Wage Stickiness," American Economic Review, 95(1), 50-65.

- (2005b): "Employment Fluctuations with Equilibrium Wage Stickiness," American Economic Review, 95, 50-65.

Hall, R. E., and P. R. Milgrom (2008): "The Limited Influence of Unemployment on the Wage Bargain," American Economic Review, 98,(4), 1653-1674.

Ilut, C. L., And M. Schneider (2011): “Ambiguous Business Cycles," Working paper, Duke University and Stanford University.

LeAhy, J. V., And T. M. Whited (1996): "The Effect of Uncertainty on Investment: Some Stylized Facts," Journal of Money, Credit and Banking, 28(1), 64-83.

Leduc, S., And K. Sill (forthcoming): "Expectations and Economic Fluctuations: An Analysis Using Survey Data," Review of Economics and Statistics.

Leduc, S., K. Sill, and T. Stark (2007): "Self-Fulfilling Expectations and the Inflation of the 1970s: Evidence from the Livingston Survey," Journal of Monetary Economics, 54(2), 433-459.

Mortensen, D. T., and C. A. Pissarides (1994): "Job Creation and Job Destruction in the Theory of Unemployment," Review of Economic Studies, 61(3), 397-415.

Romer, C. D. (1990): "The Great Crash and the Onset of the Great Depression," Quarterly Journal of Economics, 105(3), 597-624. 
Rotemberg, J. J. (1982): "Sticky Prices in the United States," Journal of Political Economy, 90(6), 1187-1211.

SchaAl, E. (2012): "Uncertainty, Productivity and Unemployment in the Great Recession," Unpublished manuscript, Federal Reserve Bank of Minneapolis.

Sims, C. A., And T. Zha (1998): "Bayesian Methods for Dynamic Multivariate Models," International Economic Review, 39(4), 949-968.

Walsh, C. E. (2005): "Labor Market Search, Sticky Prices, and Interest Rate Policies," Review of Economic Dynamics, 8, 829-849.

Federal Reserve Bank of San Francisco 